San Jose State University

SJSU ScholarWorks

Master's Theses

Master's Theses and Graduate Research

Summer 2015

\title{
An Examination of Authentic Leadership, Perceived Similarity, and Leader-Member Exchange as Moderators of the Relationship between Leader and Follower Resilience
}

Joseph Edward Smith

San Jose State University

Follow this and additional works at: https://scholarworks.sjsu.edu/etd_theses

\section{Recommended Citation}

Smith, Joseph Edward, "An Examination of Authentic Leadership, Perceived Similarity, and LeaderMember Exchange as Moderators of the Relationship between Leader and Follower Resilience" (2015). Master's Theses. 4611.

DOI: https://doi.org/10.31979/etd.e8dr-w48x

https://scholarworks.sjsu.edu/etd_theses/4611

This Thesis is brought to you for free and open access by the Master's Theses and Graduate Research at SJSU ScholarWorks. It has been accepted for inclusion in Master's Theses by an authorized administrator of SJSU ScholarWorks. For more information, please contact scholarworks@sjsu.edu. 


\title{
AN EXAMINATION OF AUTHENTIC LEADERSHIP, PERCEIVED SIMILARITY, AND LEADER-MEMBER EXCHANGE AS MODERATORS OF THE RELATIONSHIP BETWEEN LEADER AND FOLLOWER RESILIENCE
}

\author{
A Thesis \\ Presented to \\ the Faculty of the Department of Psychology \\ San José State University
}

In Partial Fulfillment

of the Requirements for the Degree

Masters of Science

by

Joseph E. Smith

August 2015 
(C) 2015

Joseph E. Smith

ALL RIGHTS RESERVED 
The Designated Thesis Committee Approves the Thesis Titled

AN EXAMINATION OF AUTHENTIC LEADERSHIP, PERCEIVED SIMILARITY, AND LEADER-MEMBER EXCHANGE AS MODERATORS OF THE RELATIONSHIP BETWEEN LEADER AND FOLLOWER RESILEINCE

\author{
by \\ Joseph E. Smith \\ APPROVED FOR THE DEPARTMENT OF PSYCHOLOGY \\ SAN JOSÉ STATE UNIVERSITY
}

August 2015

Dr. Altovise Rogers Department of Psychology

Dr. Nancy Da Silva School of Management

Ms. Michelle Deneau Intuit, Inc. 


\section{ABSTRACT \\ AN EXAMINATION OF AUTHENTIC LEADERSHIP, PERCEIVED SIMILARITY, AND LEADER-MEMBER EXCHANGE AS MODERATORS OF THE RELATIONSHIP BETWEEN LEADER AND FOLLOWER RESILEINCE}

by Joseph E. Smith

The purpose of the present study was to examine the relationship between resilience and authentic leadership as well the potential spillover of a leader's resilience onto his or her followers. In addition to the direct effects of a leader's resilience on followers, potential moderators were also explored, including authentic leadership, relational demography, and leader-member exchange. Responses to an online survey from a total of 145 part- and full-time employees were analyzed using hierarchical multiple regression. Results indicated that there was a strong direct relationship between a leader' resilience and his or her authentic leadership, however there was no direct relationship between leader and follower resilience. The addition of authentic leadership as a moderator in the relationship between leader and follower resilience yielded significant results. Followers of highly authentic leaders had higher levels of resilience when their leader also had high levels of resilience. Similar results were found for the two leader-member exchange dimensions of loyalty and affect, as well as for dyads in which followers perceived high levels of cognitive similarity with their supervisor. The addition of the leader-member exchange dimensions as a moderator yielded inconsistent results, and followers' perceptions of demographic similarities with their supervisor did not significantly moderate the relationship. Explanations and implications of these findings are discussed. 


\section{ACKNOWLEDGEMENTS}

First and foremost, I would like to thank my thesis chair, Dr. Altovise Rogers, for providing guidance and encouragement throughout the thesis process. I would also like to thank Dr. Nancy Da Silva, who has not only encouraged and supported me during the thesis process, but whose advice and input have been of immeasurable value throughout my academic career. I would like to give special thanks to my thesis third committee member, Michelle Deneau, for providing support, and occasionally some much needed pressure to complete my thesis. Finally, I would like to acknowledge the boundless patience and support I received from my partner, Rene Barraza, without whom I would not have been able to achieve this incredible milestone. 


\section{TABLE OF CONTENTS}

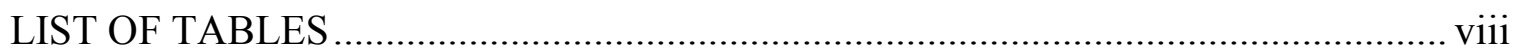

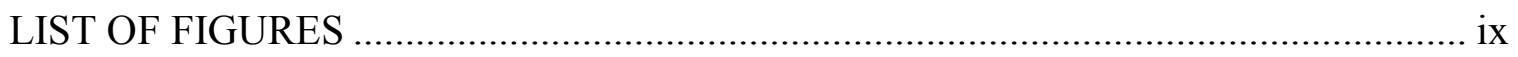

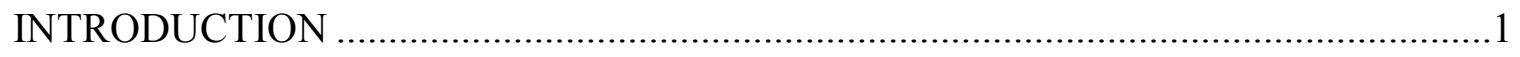

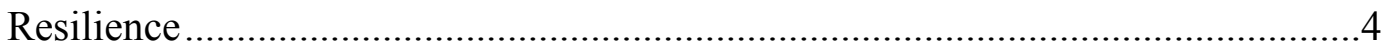

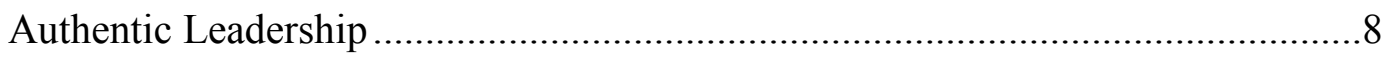

Resilience and Authentic Leadership..............................................................12

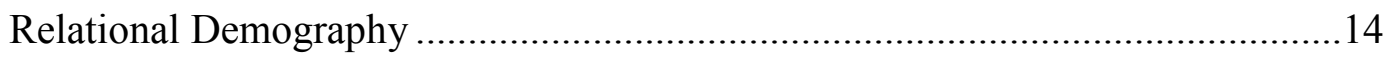

Leader-Member Exchange .............................................................................15

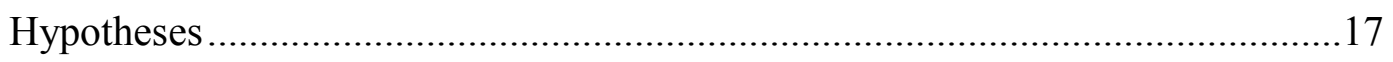

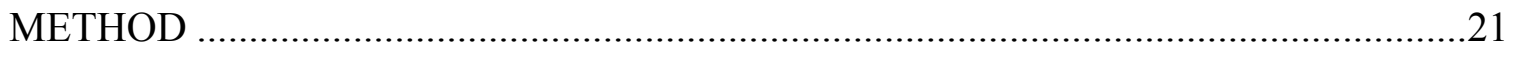

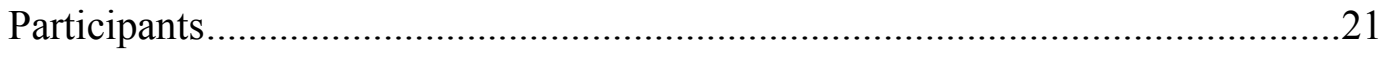

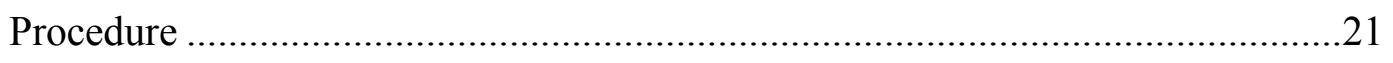

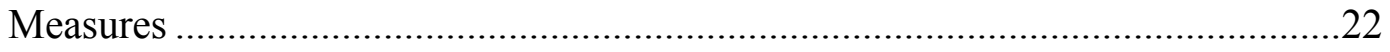

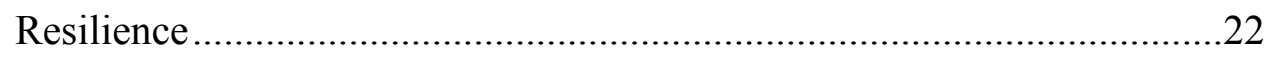

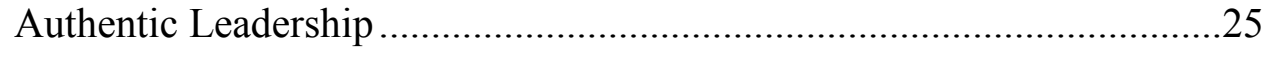

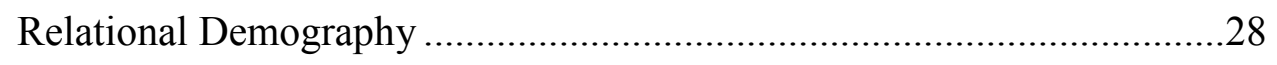

Leader-Member Exchange .........................................................................2

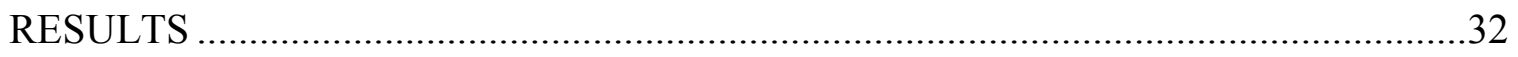

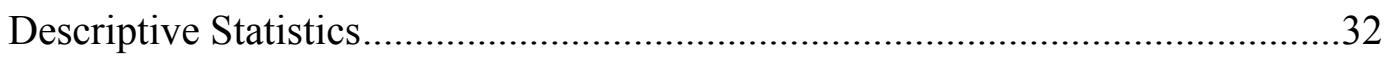

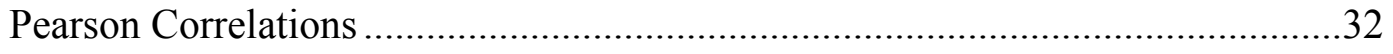

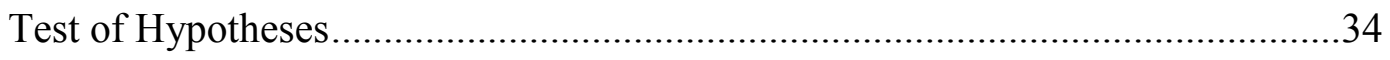


Direct Relationship Between Supervisor Resilience and Authentic Leadership

Direct Relationship Between Supervisor Resilience and Follower Resilience.

Moderating Effect of Authentic Leadership .35

Moderating Effect of Relational Demography ....................................3

Moderating Effect of Leader-Member Exchange ...................................40

DISCUSSION

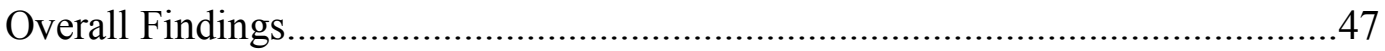

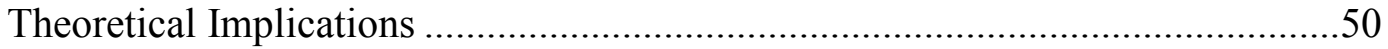

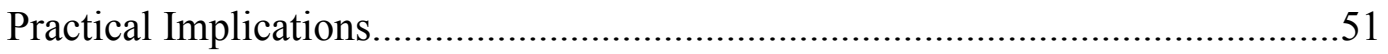

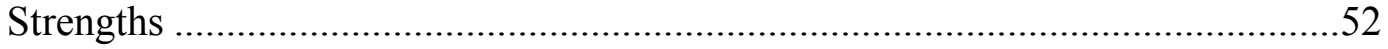

Limitations and Directions for Future Research .............................................52

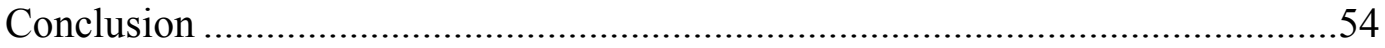

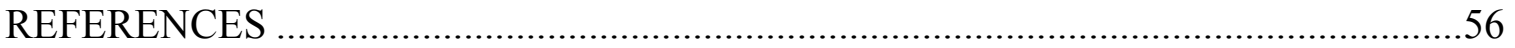

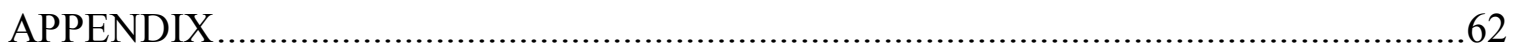

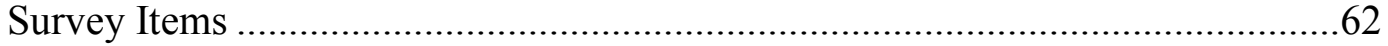




\section{LIST OF TABLES}

Table 1. Factorial Analysis of Supervisor Resilience Items: Factor Loadings .................24

Table 2. Factorial Analysis of Self-Resilience Items: Factor Loadings ..........................25

Table 3. Factorial Analysis of Authentic Leadership Items: Factor Loadings ................27

Table 4. Factorial Analysis of Perceived Similarity Items: Factor Loadings ..................29

Table 5. Factorial Analysis of Leader-Member Exchange Items: Factor Loadings .........31

Table 6. Means, Standard Deviations, and Bivariate Correlations among Studied Variables

Table 7. Hierarchical MRC for the Moderating Effect of Authentic Leadership .36

Table 8. Hierarchical MRC for the Moderating Effect of Perceived Cognitive Similarity .38

Table 9. Hierarchical MRC for the Moderating Effect of Perceived Demographic Similarity

Table 10. Hierarchical MRC for the Moderating Effect of LMX - Perceived

Contribution .41

Table 11. Hierarchical MRC for the Moderating Effect of LMX - Loyalty .43

Table 12. Hierarchical MRC for the Moderating Effect of LMX - Affect. .46 


\section{LIST OF FIGURES}

Figure 1. Diagram of Proposed Hypotheses .........................................................20

Figure 2. Moderating Effect of Authentic Leadership on the Relationship between Leader Resilience and Follower Resilience

Figure 3. Moderating Effect of Perceived Cognitive Similarity on the Relationship between Leader Resilience and Follower Resilience

Figure 4. Moderating Effect of LMX - Perceived Contribution on the Relationship between Leader Resilience and Follower Resilience

Figure 5. Moderating Effect of LMX - Loyalty on the Relationship between Leader Resilience and Follower Resilience

Figure 6. Moderating Effect of LMX - Affect on the Relationship between Leader Resilience and Follower Resilience 


\section{Introduction}

A long-standing issue posed to stakeholders of organizations has been the question of which traits and abilities allow some leaders to not only succeed, but thrive during times of uncertainty and turbulence, while others seem incapable of meeting these challenges (Hamel, 2002; Karaevli \& Hall, 2003). Dramatic fluctuations in the global economy over the past decade have made this question even more pressing as leaders find their organizations operating within an economic environment dominated by "boom and bust" cycles that appear to be increasing in frequency and magnitude (Akyüz, 2011;

Lindgren, Garcia, \& Saal, 1996; Stiglitz, 2000). These issues are of particular interest to academics, regulators, lawmakers, human resources professionals, and shareholders as they seek to better understand how the leaders of organizations can navigate through uncertainty and increasing demands on organizational performance while avoiding the legal and moral hazards that have most notably felled organizations such as Enron and Merrill Lynch (Karaevli \& Hall, 2003; Shambaugh, 2010; Walumbwa, Avolio, Gardner, Wernsing, \& Peterson, 2008).

Two topics that have emerged from this desire to understand and enhance leadership during times of uncertainty are the concept of resilience as it relates to organizational psychology and the Theory of Authentic Leadership. The general concept of resilience has been examined for many years, particularly within the fields of clinical psychology (Masten, 2001; Richardson, 2002) and child development (Tugade \& Fredrickson, 2004). The inclusion of resilience within organizational psychology is a more recent development, and its application within the field has primarily been focused 
on resilience as a subcomponent of the larger theory of positive psychological capital (Avey, Wernsing, \& Mhatre, 2011; Luthans, Vogelgesang, \& Lester, 2006). Within the organizational behavior and management fields, resilience is most commonly thought of as the ability of an individual, team, or organization to recover from adversity, setbacks, and failures (Masten, 2001; Richardson, 2002). The applicability of resilience in the workplace has gained significant attention within popular literature where business leaders view resilience as a valuable resource that can help organizations achieve success in turbulent times (Coutu, 2002; Luthans, Luthans, \& Luthans, 2004; Shambaugh, 2010).

While leadership has long been acknowledged as a key component of an organization's competitive advantage, relatively little empirical work has examined the connection between leadership and resilience (Clapp-Smith, Vogelgesang, \& Avey 2009; Harland, Harrison, Jones, \& Reiter-Palmon, 2005; Jensen \& Luthans, 2006). Despite the calls for greater understanding of the concept of resilience as it relates to business settings (Avolio \& Gardner, 2005; Luthans et al., 2004; Luthans, Vogelgesang, \& Lester, 2006; Walumbwa et al., 2008) as well as the necessity for a robust and accurate tool to measure employee resilience (Luthans, Avey, Avolio, Norman, \& Combs, 2006; Mills, Fleck, \& Kozikowski, 2013; Povah, 2012), academic research has been slow to examine this concept. This gap in our current understanding of resilience is particularly relevant to authentic leadership, given the relatively brief amount of time since the Theory of Authentic Leadership was first proposed (Avolio, \& Gardner, 2005; Avolio, Gardner, Walumbwa, Luthans, \& May, 2004; Gardner, Avolio, Luthans, May, \& Walumbwa, 2005; Walumbwa et al., 2008). 
This paper begins with a review of the current literature on the topic of resilience, aimed at defining resilience and discussing both its connection to and uniqueness from the concept of positive psychological capital, which also includes hope, optimism, and efficacy. This will lead into a discussion of the various components of resilience, and the workplace outcomes that have been linked to resilience in the workplace. Following the discussion of resilience will be a similar treatment of Authentic Leadership; this discussion will begin with a brief history and the generally established definition of the theory, followed by a discussion of the components of Authentic Leadership with a particular emphasis on the theoretical connections with resilience.

The overall purpose of this study was to address several of the gaps in the current understanding of the relationship between resilience and authentic leadership, and as a result, this study provides three valuable contributions to the current literature. The primary contribution of this study is an examination of the unique relationship between resilience and authentic leadership as well as the moderating effects of the relationship between leaders and followers. The second contribution this study makes is an examination of the spillover effects that occur between resilient leaders and their subordinates, which expands upon current understanding of the development of resilience and authentic leadership within employees. The third major contribution this study makes to current literature is an analysis of the workplace outcomes associated with high levels of resilience in employees, with an emphasis on employee engagement, and organizational commitment. 


\section{Resilience}

While the majority of early research into resilience was conducted in the fields of child and adolescent clinical psychology (Richardson, 2002), researchers in the field of organizational behavior have begun to examine the applicability of resilience within the workplace (Luthans, Avolio, Avey, \& Norman, 2007). Given the variety of fields in which resilience has been examined, it is unsurprising that a plethora of definitions and conceptualizations have been proposed. Diane Coutu (2002) identified three common characteristics that appear to be central to the concept of resilience: (a) an acceptance of reality as it is, not as one would like it to be, (b) firmly held beliefs and values, particularly in terms of finding meaning in one's life and environment, and (c) the ability to adapt and reorient in difficult situations and in the face of significant change. Using these characteristics as a basis for the definition of resilience in the workplace, Luthans described resilience as the "positive psychological capacity to rebound, to 'bounce back' from adversity, uncertainty, conflict, failure, or even positive change, progress and increased responsibility" (2002, p. 702). A key component of Luthans' definition is the inclusion of resilience within the broader framework of positive psychological states.

One of the contributing factors driving early interest in resilience as it pertains to organizational behavior was the repeated calls for a refocusing of workplace psychology, devoting less attention to negative characteristics and shifting towards the positive aspects of people and organizations (Luthans, 2002; Seligman, 2002). Luthans first attempted to address the call for a refocusing of attention on positive psychology in his 2002 paper and proposed that resilience, along with the related but distinct concepts of 
confidence and hope, would serve as excellent potential measures of positive psychological behavior. Luthans et al. went on to develop the multi-dimensional concept of positive psychological capital (Luthans et al., 2004; Luthans et al., 2007).

Positive psychological capital has been presented as an extension of human capital theory, and is described as encompassing four states that are designed to measure whom an individual is; as opposed to social and human capital, which focus primarily on who or what an individual knows. The four components of positive psychological capital include confidence, hope, optimism, and resilience (Luthans et al., 2004; Luthans et al., 2007; Mills, Fleck, \& Kozikowski, 2013).

Several studies have found positive outcomes associated with the composite measure of positive psychological capital, including a meta-analysis confirming that positive psychological capital was related to organizational commitment, job satisfaction, and employee well-being (Avey, Reichard, Luthans, \& Mhatre, 2011). These results are consistent with a study conducted by Peterson, Walumbwa, Byron, and Myrowitz (2009) who found that the combined measure of the three positive psychological states of hope, optimism, and resilience had a positive, indirect effect on company performance when mediated by transformational leadership. Although individual correlations for each psychological state were reported in Peterson's article, the individual states were not examined separately in regards to their relationship with company performance or transformational leadership (Peterson, et al., 2009). Likewise, the meta-analysis conducted by Avey, Reichard, et al. (2011) did not provide results for the individual 
dimensions of positive psychological capital, and instead only reported results for the higher level construct.

While resilience has been explored as a dimension of positive psychological capital, it has received little attention as a distinct concept that has a unique and important contribution to authentic leadership. One concern raised by researchers has been that the inclusion of resilience within the larger construct of positive psychological capital may lead some researchers and practitioners to underestimate the important role resilience can play within the workplace (Mills et al., 2013). Despite strong commonalties between the four components of positive psychological capital, there are several key differentiating characteristics of resilience. One of the key differentiators between resilience and the other factors of positive psychological capital is the staunch acceptance of reality as it is currently, whereas optimism and hope are both solely focused on positive expectations for the future (Luthans et al., 2004; Luthans, Vogelgesang, \& Lester, 2006).

Another one of the most important differentiators of resilience is that unlike the other components of positive psychological capital, it is both proactive, and more importantly, reactive in nature (Clapp-Smith et al., 2009; Luthans, Vogelgesang, \& Lester, 2006). Optimism, hope, and confidence focus on an individual's expectation of future performance, while resilience is primarily focused on how well an individual has recovered from past events. Resilient individuals not only bounce back from difficult situations or significant changes, but they reflect upon those situations, internalizing lessons that allow them to better face challenges they encounter in the future (Luthans, Avey, et al., 2006). This ability of an individual to monitor their current environment and 
not only identify, but cope with "risk factors that may otherwise be viewed as threats that increase the probability of negative outcomes or decrease the probability of positive ones" are valuable skills that, otherwise, are not captured in other dimensions of positive psychological capital (Youssef \& Luthans, 2007, p. 780).

The retrospective nature of resilience also supports the idea that resilience has a synergistic relationship with the other components of positive psychological capital (Luthans et al., 2007). This synergistic effect is what has prompted many researchers to link positive psychological capital with the broaden and build theory, which suggests that increases in an individual's positive psychological state can have both within-person, as well as between-person improvements with other psychological states (Luthans, 2002; Mills et al., 2013). The broaden and build theory suggests that resilience may play an important role as the precursor in the process of strengthening other positive emotions. For instance, an individual who is able to effectively recover from a challenge is more likely to have higher self-efficacy when confronted with similar situations in the future.

Supporting the assertion that resilience has an important and unique role in organizational behavior research is a study conducted by Youssef and Luthans (2007) who found that employees with higher levels of resilience were more committed to their organization, and reported higher levels of job satisfaction. Youssef and Luthans included hope and optimism in their analyses, and while the results for hope and optimism were similar to those for resilience, their methodological approach highlights the need to examine these concepts individually to better understand their complex interactions. Resilience has also been linked to successful coping with stress (Zunz, 
1998), and flourishing under hardship (Ryff \& Singer, 2003), two outcomes that are considered vital to organizational success (Mills et al., 2011). Although these results are encouraging, there still exists a relative dearth of knowledge informing us of the unique role that resilience plays in organizational behavior, particularly in the field of leadership. Numerous leadership theories have been conceptually linked to resilience, but empirical tests of these relationships have lagged (Avolio, \& Gardner, 2005; Gardner et al., 2005; Luthans, Vogelgesang, \& Lester, 2006; Walumbwa et al., 2008).

\section{Authentic Leadership}

There is certainly no lack of leadership theories present in both academic and popular literatures, and understandably many of these theories overlap and have communalities. Several theories have been presented, including transformational leadership (Bass, 1985), charismatic leadership (Conger \& Kanungo, 1987), servant leadership (Greenleaf, 1977), and more recently, authentic leadership (Avolio \& Gardner, 2005). Authentic leadership is thought to encompass many of the fundamental aspects of each of these forms of leadership (Avolio \& Gardner, 2005), and thus provides an excellent conceptual starting point for examining the linkage between resilience and leadership.

Consistent with the general trend within leadership research, the Theory of Authentic Leadership has gained increasing attention in the past decade, largely due to major failures in organizations such as Enron and Merrill Lynch (Shambaugh, 2010; Walumbwa et al., 2008). Research investigating authentic leadership has linked this form of leadership to several important organizational outcomes, and in particular outcomes 
associated with follower performance and attitudes. Several studies have linked authentic leadership to higher levels of follower job satisfaction (Jensen \& Luthans, 2006;

Giallonardo, Wong, \& Iwasiw, 2010; Walumbwa et al., 2008; Wong \& Cummings, 2009), higher levels of organizational commitment among followers (Jensen \& Luthans, 2006; Walumbwa et al., 2008), and increased job performance in followers (Walumbwa et al., 2008; Wong \& Cummings, 2009). Authentic leadership has also been linked to lower levels of burnout within followers (Wong \& Cummings, 2009), and Walumbwa et al. (2008) found that those followers who rated their supervisor as being a more authentic leader were themselves more likely to engage in organizational citizenship behaviors, such as helping coworkers even when not required to do so. These results highlight the positive impact that authentic leadership has on an organization, and the importance of understanding the mechanisms by which authentic leadership can be developed within individuals, as well as its spillover from leader to follower.

Authentic leadership, at its most fundamental level, is the congruence of a leader's self-concept and his or her actions (Gardner et al., 2005; Shamir \& Eliam, 2005). As its name suggests, authenticity is at the core of authentic leadership, and is based upon the ancient Greek maxim "to thine own self be true." Authentic leaders lead from their convictions, and remain true to their personal values and beliefs, even during times of stress and challenge, when inauthentic leaders may be more likely to compromise their personal convictions (Avolio \& Gardner, 2005). Numerous definitions of authentic leadership have been suggested; however, the definition proposed by Walumbwa et al. 
integrates many of the early conceptualizations of the construct, and establishes a generally accepted definition of authentic leadership as

A pattern of leader behavior that draws upon and promotes both positive psychological capacities and a positive ethical climate, to foster greater selfawareness, an internalized moral perspective, balanced processing of information, and relational transparency on the part of leaders working with followers, fostering positive self-development (2008, p. 94).

This definition touches upon several key components of authentic leadership, including the four dimensions that underlie the higher order construct of authentic leadership, as well as the important role that followers play in the development and demonstration of authentic leadership (Avolio \& Gardner, 2005). The four dimensions of authentic leadership that are most commonly used in conceptualizations and measures of the construct are self-awareness, relational transparency, balanced processing, and an internalized moral perspective (Avolio \& Gardner, 2005; Gardner, et al., 2005; Neider \& Schriesheim, 2011). Although the four dimensions of authentic leadership are considered distinct, there exists a complex interaction between these dimensions (Walumbwa et al., 2008), as well as the role that the follower plays in determining how a leader manifests behaviors related to each dimension (Avolio \& Gardner, 2005; Ilies, Morgeson, \& Nahrgang, 2005).

One of the most important characteristics of authentic leadership is the heightened self-awareness that authentic leaders possess (Avolio \& Gardner, 2005). Authentic leaders are aware of their motives, emotions, and values; this awareness is holistic in nature, with authentic leaders being equally able to identify their weaknesses as well as their strengths (Gardner et al., 2005). This heightened sense of self-awareness is 
instrumental to a leader's ability to process information in a balanced manner (Avolio \& Gardner, 2005; Michie \& Gooty, 2005). Leaders must be able to understand their own motivations and emotions, and how their personal perspective will shape the way in which they react to a given situation.

Authentic leaders also have high levels of self-regulation, whereby they are able to (a) internalize their morals and values, (b) assess their own actions within this internalized framework, and (c) identify discrepancies and formulate actions needed to reconcile those discrepancies (Avolio \& Gardner, 2005). This ability to self-regulate is what allows leaders to build upon their self-awareness, and process both external and internal information in a balanced and unbiased way (Gardner et al., 2005). Authentic leaders "are able to more objectively evaluate and accept both positive and negative aspects, attributes and qualities of themselves, including skill deficiencies, suboptimal performance, and negative emotions" (Gardner et al., 2005, p. 356). This combination of self-regulation and self-awareness is often referred to as an internalized moral perspective.

When leaders utilize their internalized moral perspective and balanced processing to achieve consistency in their words and actions, this results in perhaps the most salient characteristic of authentic leadership: authentic behavior. Kernis (2003), as well as Avolio and Gardner (2005), suggest that when followers perceive their leader as behaving authentically, this positive modeling results in a spillover effect in which authentic leaders are able to foster positive affective states in their followers. Avolio and Gardner (2005) link the increased credibility and trustworthiness that authentic leaders 
achieve, with research conducted by Bandura (1997), suggesting that these features of authentic leadership are both salient and valued by followers, thus increasing followers' motivation to learn from their leader. Ilies et al. (2005) offer emotional contagion as an additional mechanism through which authentic leaders influence the behaviors of their followers. Ilies et al. (2005) build upon previous research that has found positive emotions are more likely to spread within an organization (Fredrickson, 2003), suggesting that authentic leaders, with their increased positive affective states, will engender positive emotions within those individuals who work with them. Ilies et al. (2005) also suggest that authentic leaders focus their efforts on the values and well-being of their followers, leading to higher levels of positive affect and satisfaction. Research by Rego, Sousa, Marques, and eCunha (2014) found that the relationship between supervisors' authentic leadership and employee creativity was partially mediated by positive affect, providing support for the assertion that authentic leadership has a spillover effect. This spillover effect is a particularly important aspect of authentic leadership theory given that similar theories of leadership such as transformational, charismatic, or servant leadership do not explicitly consider this interaction between leader and follower (Avolio \& Gardner, 2005; Gardner et al., 2005; Walumbwa et al., 2008).

\section{Resilience and Authentic Leadership}

While most conceptualizations of authentic leadership include the four dimensions of positive psychological capital, relatively few researchers have examined the unique relationship between resilience and authentic leadership. Indeed, some 
research has ignored this component of positive psychological capital in favor of greater examination of the other three components (Avolio et al., 2004). However, given the conceptual framework of authentic leadership, there are strong indications that resilience may play a strong role in authentic leadership development (Jensen \& Luthans, 2006).

The first indication that resilience is tightly coupled with authentic leadership is the temporal component of authentic leadership, which suggests that authentic leadership can be nurtured, and develops over an individual's lifetime (Avolio \& Gardner, 2005; Shamir \& Eilam, 2005). Authentic leadership is often theorized as being triggered by a critical life event (Gardner et al., 2005). While traditionally these trigger events were thought to be purely negative in nature (e.g., childhood trauma, injury or illness, involuntary turnover from job), recent research has suggested that trigger events can also be positive in nature (e.g., promotions with expanded responsibilities, voluntarily changing careers, and meeting leaders who inspire with their own authentic style) (Gardner et al., 2005).

In Shamir and Eilam's (2005) discussion of the role that life stories play in authentic leadership development, they point out that strong leaders often face significant struggles, and incorporate those struggles into their leadership style. Trigger events that occur within organizational settings challenge leaders' ability to develop innovative and unconventional solutions, and may come as a result of either internal or external pressures (Gardner et al., 2005). Individuals who 'bounce back' from difficult circumstances often integrate that conflict and success into their personal narrative, increasing their self-awareness (Gardner et al., 2005; Shamir \& Eilam, 2005). This 
resiliency not only allows individuals to incorporate critical life events into their personal narrative, but it aids in the creation of heuristics, which the individual can quickly apply to future difficult circumstances. This ability of resilience to reinforce self-efficacy is one reason why positive psychological capital and authentic leadership have been so closely linked to the broaden-and-build model of positive emotions (Avolio \& Gardner, 2005).

The spillover effects described in the broaden and build literature suggests that positive psychological states, such as resilience, hope, and optimism, influence each another within an individual (Harland et al., 2005; Richardson, 2002; Tugade \& Fredrickson, 2004), and there is some support for the idea that these positive psychological states can be transmitted to other individuals within the workplace (Rego, Sousa, Marques, \& eCunha, 2014). The proposition that authentic leadership facilitates the spillover of positive psychological states (Avolio \& Gardner, 2005; Rego, Sousa, Marques, \& eCunha, 2014), and that resilience has synergistic effects with hope, optimism, and self-efficacy (Luthans, 2002; Mills et al., 2013), suggests that authentic leaders can foster resilience within their followers, which in turn may encourage those followers to develop their own authentic leader behavior. There is research that has shown that leader behavior has a direct impact on the follower's level of resilience, which further suggests a strong connection between the two constructs (Avey, Avolio, \& Luthans, 2011; Harland et al., 2005; Peterson et al., 2009).

\section{Relational Demography}

As mentioned above, a critical component of authentic leadership is the relationship that exists between the leader and their followers. The dyadic relationship 
proposed in the theory of authentic leadership does not explicitly discuss how the strength or quality of the relationship between leader and follower may impact the spillover of authentic leader traits, and thus ignores potential important moderators to the relationship. One such moderator is relational demography, which explores the impact that age, gender, and ethnicity have on the dyadic relationship between supervisor and subordinate (Carroll \& Khessina, 2005; Tsui, Egan, \& O'Reilly, 1992; Tsui \& O'Reilly, 1989). Previous literature in the field of relational demography has found that dissimilarity in dyads resulted in lower appraisals of performance from supervisors, increased role ambiguity as reported by subordinates, and lower levels of personal attraction on the part of supervisors toward their subordinates (Tsui et al., 1992). Although previous literature has explored the moderating effect of relational demography for several theories of leadership (Douglas, 2012; Shin, \& Zhou, 2007), there appears to be an absence of published studies exploring the interaction between relational demography as it relates to authentic leadership.

\section{Leader-Member Exchange}

Much like with relational demography, the theory of leader-member exchange explores the relationships that occurs between leaders and their followers (Gerstner \& Day, 1997; Tsui \& Egan, 1994; Tsui, Xin, \& Egan, 1994). Leader-member exchange challenges the assumption that leaders treat all of their followers as a collective group, and instead suggests that leaders vary the quality of their relationship with followers (Dansereau, Graen, \& Haga, 1975; Graen \& Uhl-Bien, 1995). This variation in the quality of exchange between leader and followers creates an in-group, whose higher 
quality exchanges with their leader result in more information, influence, and concern from the leader. This is contrasted by those in the out-group, whose lower quality exchange does not necessarily mean they receive unfair treatment; however, the relationship between leader and follower is much more transactional in nature. Research has found that high quality exchanges between leaders and followers have several beneficial outcomes, including lower turnover, higher frequency of promotions, greater organizational commitment, and better job attitudes (Graen \& Uhl-Bien, 1995). Leadermember exchange has been also been examined in relation to other leadership theories, such as transformational leadership theory (Graen \& Uhl-Bien, 1995), however relatively little research has examined the role of leader-member exchange within the framework of authentic leadership.

Research conducted by Wang, Sui, Luthans, Wang, and Wu (2014) examined the role of leader-member exchange as a mediator in the relationship between authentic leadership and follower job performance, as well as the moderating effects of positive psychological capital on the relationship between leader-member exchange and follower job performance. Wang et al. (2014) reported that leader-member exchange served as a partial mediator between authentic leadership and employee job performance, suggesting that the positive outcomes associated with authentic leadership are at least in part dependent on the quality of the relationship between leader and follower. Wang et al. (2014) also found that positive psychological capital served as a moderator, such that the relationship between leader-member exchange and performance increases as the followers' positive psychological capital decreases. These results suggest that leader- 
member exchange plays an important role in the relationship between authentic leadership and positive psychological capital; however scant additional research has built upon these findings.

\section{Hypotheses}

The goal of this paper is to respond to calls for additional evidence that leader resilience is a desirable and testable state (Jensen \& Luthans, 2006; Luthans et al., 2007; Povah, 2012) that will allow organizations to develop current and potential leaders, and improve organizational performance (Peterson et al., 2009; Shambaugh, 2010) (see

Figure 1 for a diagram of the proposed hypotheses). Given the multi-faceted and interpersonal nature that typifies authentic leadership (Avolio \& Gardner, 2005), it is expected that the relationship between resilience and leadership in general will be strongest within the authentic leadership framework. This is not to suggest that resilience is not also connected with other forms of leadership; indeed, it would be expected that resilience would be strongly related to most theories of leadership. The synergistic effect of resilience within the theory of psychological capital, as well as the need for effective leaders to cope with failures and setbacks suggests that resilience plays a key role in the relationship between positive psychological capital and authentic leadership.

Furthermore, the accumulation of life experiences is an integral component of authentic leadership, and resilient individuals are better able to cope with, and learn from their experiences in a way that allows them to confront future challenges more effectively. Thus, it is hypothesized that resilient individuals will display more traits associated with authentic leadership than individuals who are less resilient. 
Hypothesis 1: Supervisor resilience will positively predict the four dimensions of authentic leadership (self-awareness, relational transparency, balanced processing, and an internalized moral perspective).

Leaders' positive psychological states have been shown to spillover onto subordinates' attitudes through positive modeling and emotional contagion (Aviolo \& Gardner, 2005; Rego, Sousa, Marques, \& eCunha, 2014). In addition, Harland et al. (2005) found that transformational leadership behaviors were related to higher levels of follower resilience. Although Harland et al. findings were limited to transformational leadership, Avolio and Gardner (2005) have proposed that many of the features of transformational leadership, particularly those concerned with follower outcomes, are conceptually similar to that of authentic leadership. Given the conceptual similarities between these two theories of leadership, and the strong link between positive psychological capital and authentic leadership, it is expected that high levels of resilience within an authentic leader should encourage high levels of resilience within that leader's subordinates. In addition, given the strong role that authentic leadership plays in this relationship, it is expected that authentic leadership levels will moderate the relationship between resilience of the leader and resilience of the follower, such that the relationship is stronger when the leader is authentic.

Hypothesis 2: Leader resilience will have a positive relationship with follower resilience.

Hypothesis 3: The positive relationship between leader resilience and follower resilience will be moderated by the supervisor's authentic leadership behaviors, such 
that the relationship between supervisor resilience and follower resilience will be stronger for leaders with high as compared to low authentic leadership.

Finally, the theories of relational demography and leader-member exchange indicate that leaders do not treat their followers as a homogenous collective, but instead vary the quality of their relationships, and that such variance has an impact on followerrelated outcomes. Given that positive modeling and emotional contagion are the proposed mechanisms through which authentic leaders transfer their authentic leadership traits onto followers, and that such transfer is most likely to occur among dyads with high-quality relationships, it is hypothesized that both relational demography and leadermember exchange will serve as moderators to the relationship between leader resilience and follower resilience.

Hypothesis 4: The relationship between leader resilience and follower resilience will be moderated by the strength of the dyad's working relationship, such that the relationship between leader resilience and follower resilience will be strongest within dyads that have (a) more perceived demographic similarities between leader and follower and (b) dyads with higher quality leader-member exchange. 


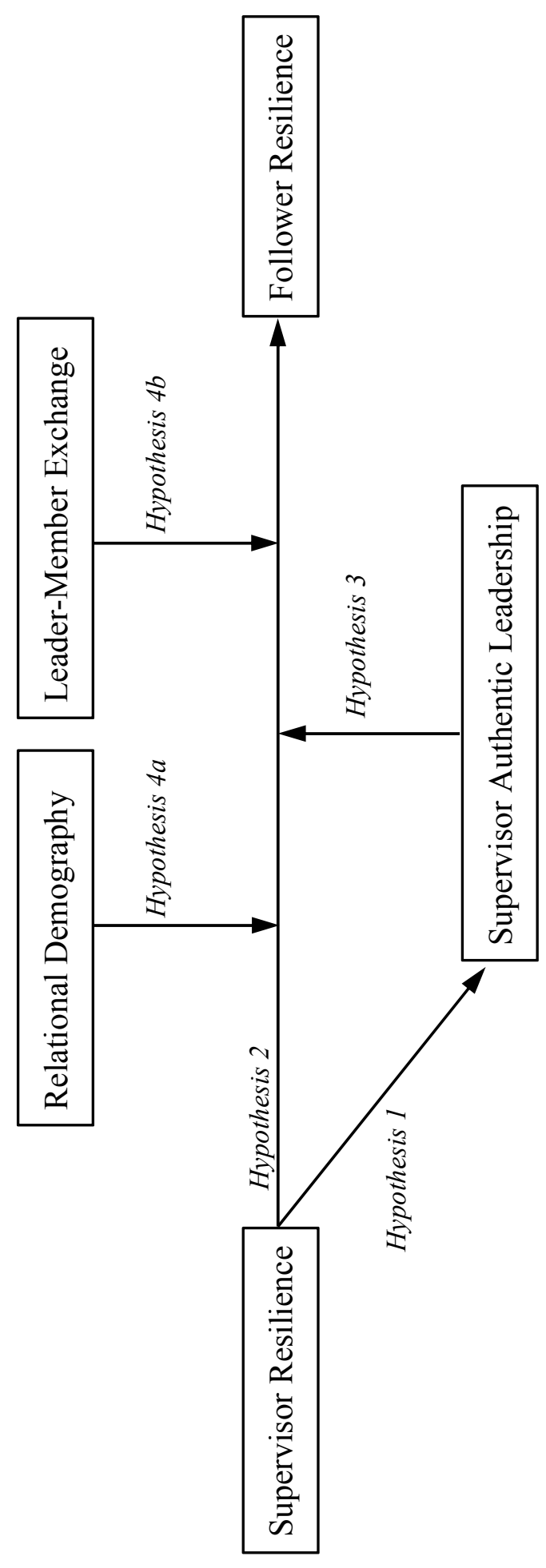

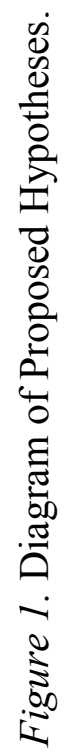




\section{Method}

\section{Participants}

Participants in this study were undergraduate students enrolled in upper division business courses at a public university located on the west coast of the United States. The participants were recruited from a research pool in which students participated in research studies as part of their course requirements. Students were also recruited from specific business courses and were given a nominal amount of extra credit for completing the survey.

\section{Procedure}

Eighty-two participants were drawn from a research experience pool, with an additional 99 students recruited from specific courses within the College of Business. An anonymous link to the online survey was posted on the course website and the research pool website for those students who chose to participate. Of the 181 completed surveys, two were removed due to excessive missing data, and one was removed because the student failed to follow the posted directions for completing the survey. Finally, 33 responses were excluded from analyses because the students were not employed either part-time or full-time, resulting in a final sample size of 145 students.

The average age of participants was $22.9, \mathrm{SD}=3.68$. Of those respondents that were employed, $80 \%$ reported working part-time, with $20 \%$ reporting they were employed full-time. The number of hours worked per week was assessed with grouped categories based upon the respondents' employment status. Respondents that indicated they worked part-time were given the response options of Less than 1 hour per week, 1-5, 
6-10, 11-15, 16-20, 21-25, 26-30, and More than 30 hours per week. The majority of respondents who worked part-time reported working between 16 to 25 hours a week, with $31 \%$ of respondents selecting 16 to 20 hours a week, and $28.4 \%$ reporting they worked 21 to 25 hours per week. Only $18.9 \%$ of respondents reported working more than 26 hours a week, while 29.4 reported working fewer than 16 hours per week. Respondents who indicated they worked full-time were given the response options of Less than 15 hour per week, 15-20, 21-25, 26-30, 31-35, 36-40, and More than 40 hours per week. The majority of respondents that worked full-time reported working 36 hours or more a week, with $48.3 \%$ of respondents selecting 36 to 40 hours a week, and 34.5\% reporting they worked more than 40 hours per week. Participants' tenure within their organization was assessed with grouped categories of Less than 6 months, 6 months to 1 year, 1.5 to 2 years, 2.5 to 3 years, and More than 3 years. Most respondents reported they had worked for their organization for 1.5 to 2 years. The gender of respondents was balanced, with $49 \%$ female, and 51\% male. Finally, of the 145 respondents that reported their ethnicity, 15.9\% were White/Caucasian, 2.8\% African American, 22.8\% Hispanic/Latino, 36.6\% East Asian / Asian American, 2.1\% South Asian / Indian American, 6.2\% Middle Eastern or Arab American, 0.7\% Native American, 3.4\% Pacific Islander, and 9.7\% selecting Other.

\section{Measures}

Resilience. Resilience was assessed using the ten-item Revised Connor-Davidson Resilience Scale (Gucciardi, Jackson, Coulter, \& Mallett, 2011), and adapted to measure the participants' self-assessment of their resilience, as well as the participants' assessment 
of their supervisor's resilience (see Appendix for the full listing of the items used in this study). Example items are, "I tend to bounce back after illness or hardship," and "My supervisor is not easily discouraged by failure." Participants were asked to respond using the same five-point Likert-type response as for measurement of AL (authentic leadership) for ease of participation ( $1=$ Strongly disagree, $2=$ Disagree, $3=$ Neither agree nor disagree, 4=Agree, 5=Strongly agree). The ten-item Revised Connor-Davidson Resilience Scale is conceptualized as being uni-dimensional; exploratory factor analyses using principal component analysis with Varimax rotation and Kaiser normalization were conducted on the 10 items measuring supervisors' resilience, as well the 10 items measuring respondents' self-assessment of their resilience. The results of the analysis of supervisor's resilience were consistent with the literature (Gucciardi et al., 2011), with the 10 items loading onto a single factor that explained a total of $67.10 \%$ of the variance. The eigenvalues and component matrix for supervisor resilience are presented in Table 1. The mean of the 10 items measuring supervisor resilience were calculated to create a single score of the supervisor's resilience. The analysis of the 10 items measuring selfassessment of resilience yielded two factors, explaining a total of $56.65 \%$ of the variance. The eigenvalues and component matrix for self-resilience are presented in Table 2. The first factor explained $28.70 \%$ of the variance, while the second factor explained $27.95 \%$ of the variance. A review of the component matrix does not provide a clear conceptual differentiation between the two factors identified in the analysis, and so to remain consistent with current literature, the 10 self-resilience items were combined into a single measure of respondents' resilience. Both the supervisor and self-resilience scales appear 
to be internally consistent, with supervisor resilience at $\alpha=.94$ and self-resilience at $\alpha=$ .86 .

Table 1

Factorial Analysis of Supervisor Resilience Items: Factor Loadings

\begin{tabular}{|c|c|c|}
\hline \multicolumn{2}{|r|}{ Items } & $\begin{array}{c}\begin{array}{c}\text { Factor } \\
\text { Loadings }\end{array} \\
1\end{array}$ \\
\hline 6 & My supervisor can achieve goals despite obstacles. & .864 \\
\hline 5 & My supervisor tends to bounce back after illness or hardship. & .862 \\
\hline 7 & My supervisor can stay focused under pressure. & .858 \\
\hline 10 & My supervisor can handle unpleasant feelings. & .846 \\
\hline 2 & My supervisor can deal with whatever comes. & .828 \\
\hline 8 & My supervisor is not easily discouraged by failure. & .825 \\
\hline 4 & My supervisor believes that coping with stress can strengthen them. & .822 \\
\hline 1 & My supervisor can adapt to change. & .193 \\
\hline 9 & My supervisor thinks of themself as strong person. & .769 \\
\hline 3 & My supervisor tries to see the humorous side of problems. & .711 \\
\hline & $\begin{array}{r}\text { Percent of Variance } \\
\text { Eigenvalue }\end{array}$ & $\begin{array}{c}67.10 \\
6.71\end{array}$ \\
\hline
\end{tabular}

Note. $n=145$ Extraction Method: Principal Component Analysis.

Rotation Method: Varimax.

Total Variance $=67.10 \%$ 
Table 2

Factorial Analysis of Self-Resilience Items: Factor Loadings

\begin{tabular}{|c|c|c|c|}
\hline & \multirow[b]{2}{*}{ Items } & \multicolumn{2}{|c|}{ Factor Loadings } \\
\hline & & 1 & 2 \\
\hline 8 & I am not easily discouraged by failure. & .763 & .135 \\
\hline 9 & I think of myself as strong person. & .758 & .231 \\
\hline 7 & I can stay focused under pressure. & .731 & .184 \\
\hline 10 & I can handle unpleasant feelings. & .710 & .280 \\
\hline 6 & I can achieve goals despite obstacles. & .562 & .442 \\
\hline 2 & I can deal with whatever comes. & .275 & .761 \\
\hline 1 & I adapt to change. & .205 & .755 \\
\hline 3 & I try to see the humorous side of problems. & .113 & .691 \\
\hline 4 & Coping with stress can strengthen me. & .201 & .656 \\
\hline 5 & I tend to bounce back after illness or hardship. & .433 & .599 \\
\hline & Percent of Variance & 28.70 & 27.95 \\
\hline & Eigenvalue & 2.87 & 2.80 \\
\hline
\end{tabular}

Note. $n=145$ Extraction Method: Principal Component Analysis.

Rotation Method: Varimax.

Total Variance $=56.65 \%$

Authentic leadership (AL). Authentic leadership was assessed using the 14-item Authentic Leadership Inventory (Neider \& Schriesheim, 2011) and adapted to focus participants' assessment on their immediate supervisor's authentic leadership.

Participants were asked to respond to statements using a five-point Likert-type response (1=Strongly disagree, 2=Disagree, 3=Neither agree nor disagree, 4=Agree, 5=Strongly agree). The Authentic Leadership Inventory is divided into the four dimensions of selfawareness $(\mathrm{S})$, relational transparency $(\mathrm{R})$, internalized moral perspective $(\mathrm{M})$, and 
balanced processing (B). Example items for self-awareness are, "My supervisor is clearly aware of the impact he/she has on others," and for relational transparency, "My supervisor clearly states what he/she means." Example items for internalized moral perspective are, "My supervisor uses his/her core beliefs to make decisions," and for balanced processing, "My leader asks for ideas that challenge his/her core beliefs." Although the Authentic Leadership Inventory contains the four dimensions that are theorized to constitute authentic leadership, Walumbwa et al. (2008) obtained support for combining the 14 items into a single, higher-order measure of authentic leadership. Exploratory factor analyses using principal component analysis with Varimax rotation and Kaiser normalization were conducted on the 14 items measuring authentic leadership to test the dimensionality of authentic leadership within this study. The results of the analysis were consistent with Walumbwa et al. (2008) findings, with the 14 items loading onto a single factor that explained a total of $65.05 \%$ of the variance. The eigenvalues and component matrix are presented in Table 3 . The mean of the 14 items measuring supervisor resilience were calculated to create a single score for the supervisor's authentic leadership. The internal consistency reliability of the Authentic Leadership Inventory was $\alpha=.94$. 
Table 3

Factorial Analysis of Authentic Leadership Items: Factor Loadings

Factor

Loadings

Items

1

\section{Self-Awareness}

1 My supervisor describes accurately the way that others view his/her abilities.

2 My supervisor shows that they understand their strengths and weaknesses.

3 My supervisor is clearly aware of the impact he/she has on others.

\section{Relational Transparency}

3 My supervisor expresses his/her ideas and thoughts clearly to others.

1 My supervisor clearly states what he/she means.

2 My supervisor openly shares information with others.

\section{Internalized Moral Perspective}

2 My supervisor uses his/her core beliefs to make decisions.

1 My supervisor shows consistency between his/her beliefs and actions.

4 My supervisor is guided in his/her actions by internal moral standards.

3 My supervisor resists pressures to do things contrary to his/her beliefs.

\section{Balanced Processing}

4 My supervisor encourages others to voice opposing points of view.

2 My supervisor carefully listens to alternative perspectives before reaching a conclusion.

3 My supervisor objectively analyzes relevant data before making a decision.

1 My supervisor asks for ideas that challenge his/her core beliefs.

Note. $n=145$ Extraction Method: Principal Component Analysis.

Rotation Method: Varimax.

Total Variance $=65.05 \%$ 
Relational demography. Participants' perceived similarity with their supervisor was assessed with four questions, two of which were taken directly from Turban and Jones (1988) article, while the other two were adapted versions that were specifically targeted at demographic similarities. Examples of the perceived similarity to supervisor items include "My supervisor and I see things in much the same way," and "My supervisor and I are similar in age," with participants using a five-point Likert-type scale for all four items $(1=$ Very dissatisfied, $2=$ Dissatisfied, $3=$ Undecided or neutral, 4=Satisfied, $5=$ Very satisfied). Exploratory factor analyses using principal component analysis with Varimax rotation and Kaiser normalization were conducted on the four items measuring perceived similarity with supervisor. The analysis identified two factors that explained $75.03 \%$ of the variance. The eigenvalues and component matrix are presented in Table 4.

The first factor contained the two items taken directly from Turban and Jones article (1988), and explained $43.20 \%$ of the variance; these items appeared to measure the respondents' perceived similarity with their supervisor in regards to cognitive style. The second factor contained the two adapted items that were focused on demographic similarities, and explained $31.83 \%$ of the variance. Given the two-factor solution, mean scores were computed for both the cognitive and the demographic dimensions of perceived similarity. Although the perceived cognitive similarity items had a high internal reliability estimate of $\alpha=.85$, the perceived demographic similarity items were much lower at $\alpha=.42$. 
Table 4

Factorial Analysis of Perceived Similarity Items: Factor Loadings

\begin{tabular}{|c|c|c|c|}
\hline & \multirow[b]{2}{*}{ Items } & \multicolumn{2}{|c|}{ Factor Loadings } \\
\hline & & 1 & 2 \\
\hline \multicolumn{4}{|c|}{ Cognitive } \\
\hline 2 & My supervisor and I are alike in a number of areas. & .930 & .083 \\
\hline 1 & My supervisor and I see things in much the same way. & .918 & .151 \\
\hline \multicolumn{4}{|c|}{ Demographics } \\
\hline 4 & My supervisor and I are similar in regards to ethnicity. & .075 & .801 \\
\hline \multirow[t]{3}{*}{3} & My supervisor and I are similar in age. & .123 & .776 \\
\hline & Percent of Variance & 43.20 & 31.83 \\
\hline & Eigenvalue & 1.73 & 1.27 \\
\hline
\end{tabular}

Note. $n=145$ Extraction Method: Principal Component Analysis.

Rotation Method: Varimax.

Total Variance $=75.03 \%$

Leader-member exchange (LMX). Leader-member exchange was measured using the LMX-6 developed by Schriesheim, Neider, Scandura, and Tepper (1992). The LMX- 6 contains 6 items that are divided among the three sub-dimensions of perceived contribution to the relationship (LMX-C), loyalty (LMX-L), and positive affect (LMXA). The first item used to measure the perceived contribution to the relationship was "The way my supervisor sees it, the importance of my job to his/her performance is," with participants asked to respond using a five-point Likert-type response $(1=$ Light to none-it has little effect on his/her performance, 2=Somewhat, 3=Moderate, 4=Great, $5=$ Very great-it critically affects his/her performance). The second item used to measure the perceived contribution to the relationship was "The way my supervisor sees 
me, he/she would probably say that my ability to do my job well is," with participants asked to respond to the statement using a five-point Likert-type response (1=Poor, $2=$ Below average, $3=$ Average, $4=$ Good to very good, $5=$ Exceptional $)$. Two items were used to measure the loyalty sub-dimension, an example item includes "I feel that my work goals and those of my supervisor are," with participants using a five-point Likerttype scale for both items ( $1=$ Opposite, $2=$ Different, $3=$ =Unrelated, $4=$ Similar, $5=$ The same). Two items were used to measure the positive affect sub-dimension, an example item includes "On my present job, this is how I feel about the way my supervisor and I understand each other," with participants using the same five-point Likert-type scale for both items (1=Very dissatisfied, $2=$ Dissatisfied, $3=$ =Undecided or neutral, 4=Satisfied, $5=$ Very satisfied). Exploratory factor analyses using principal component analysis with Varimax rotation and Kaiser normalization were conducted on the six items measuring leader-member exchange. Results of the analysis were inconsistent with the literature, with the six items loading onto two factors that did not align to the theorized dimensions within leader-member exchange, and explaining $66.94 \%$ of the variability. An additional confirmatory factor analysis with a forced three-factor solution was conducted, with results consistent with the theorized dimensionality of leader-member exchange. The forced three-factor solution explained $81.05 \%$ of the variance. The eigenvalues and component matrix for the three-factor solution are presented in Table 5. The first factor contained the two affect items, and explained $32.77 \%$ of the variance, the second factor contained the two loyalty items, and explained $29.15 \%$ of the variance. The third factor contained the two items measuring perceived contribution to the relationship, and 
explained $19.13 \%$ of the variance. Means were computed for each of the three dimensions of leader-member exchange. Although the affect and loyalty dimensions appear to be internally consistent, with affect at $\alpha=.82$ and loyalty at $\alpha=.81$, the perceived contribution items had a low internal reliability of $\alpha=.38$.

Table 5

Factorial Analysis of Leader-Member Exchange Items: Factor Loadings

\begin{tabular}{|c|c|c|c|}
\hline \multirow[b]{2}{*}{ Items } & \multicolumn{3}{|c|}{ Factor Loadings } \\
\hline & 1 & 2 & 3 \\
\hline \multicolumn{4}{|l|}{ Affect } \\
\hline $\begin{array}{l}5 \text { On my present job, this is how I feel about the way } \\
\text { my supervisor and I understand each other: }\end{array}$ & .881 & .149 & .162 \\
\hline $\begin{array}{l}6 \text { On my present job, this is how I feel about the way } \\
\text { my supervisor provides help on hard problems: }\end{array}$ & .815 & .404 & -.030 \\
\hline \multicolumn{4}{|l|}{ Loyalty } \\
\hline $\begin{array}{l}3 \text { My supervisor would probably say that my work } \\
\text { goals and his/hers are: }\end{array}$ & .107 & .874 & .185 \\
\hline $\begin{array}{l}4 \text { I feel that my work goals and those of my supervisor } \\
\text { are: }\end{array}$ & .445 & .787 & .111 \\
\hline \multicolumn{4}{|l|}{ Perceived Contribution } \\
\hline $\begin{array}{l}1 \text { The way my supervisor sees it, the importance of } \\
\text { my job to his/her performance is: }\end{array}$ & -.060 & .413 & .788 \\
\hline \multirow[t]{3}{*}{$\begin{array}{l}2 \text { The way my supervisor sees me, he/she would } \\
\text { probably say that my ability to do my job well is: }\end{array}$} & .559 & -.103 & .673 \\
\hline & 32.77 & 29.15 & 19.13 \\
\hline & 1.97 & 1.75 & 1.15 \\
\hline
\end{tabular}

Note. $n=145$ Extraction Method: Principal Component Analysis.

Rotation Method: Varimax.

Total Variance $=81.05 \%$ 


\section{Results}

\section{Descriptive Statistics}

The means, standard deviations, and correlations for the measured constructs are shown in Table 6. Respondents' self-reported rating of their own resilience was fairly high $(M=4.01, S D=.57)$, with respondents' ratings of their supervisor's resilience only slightly lower $(M=3.84, S D=.81)$. Respondents rated their supervisors as moderately high in authentic leadership $(M=3.73, S D=.87)$. The three dimensions comprising leader-member exchange all had similar results, with the perceived contribution to the exchange dimension having received the highest average rating $(M=3.88, S D=.70)$, followed by the loyalty dimension $(M=3.79, S D=.78)$, and finally the affect dimension $(M=3.72, S D=.95)$. The four items measuring the respondents' perceived similarity with their supervisor appear to align with the dimensions identified in the factor analysis presented in the previous section, with respondents scoring themselves as somewhat similar to their supervisor when asked if they see things in much the same way $(M=3.43$, $S D=1.07)$, and when asked if they are similar to their supervisor in a number of ways $(M$ $=3.27, S D=1.10)$. Respondents rated themselves as relatively less similar to their supervisor when asked more direct questions about similarity in terms of age $(M=2.17$, $S D=1.31)$ and ethnicity $(M=2.72, S D=1.54)$.

\section{Pearson Correlations}

As seen in Table 6, supervisor resilience was positively related to all of the moderator variables, with the strongest relationship occurring between supervisor resilience and supervisor authentic leadership $(r=.83, p<.01)$. This indicates that 


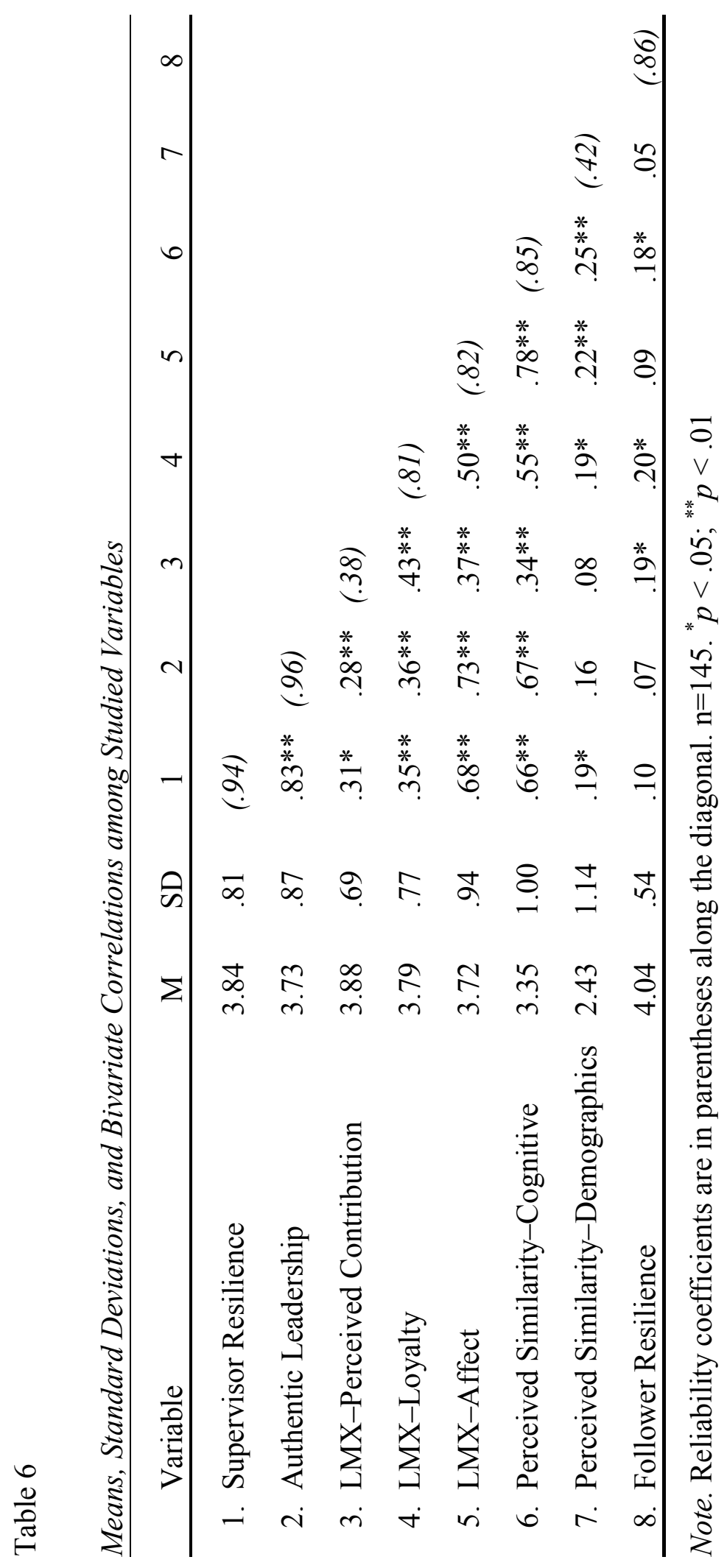


supervisors who are seen as being resilient are also perceived as being more authentic in their leadership. However, the relationship between supervisor resilience and follower resilience was non-significant $(r=.10, p=.22)$. There appears to be no direct, linear relationship between a leader's level of resilience, and the resiliency of his or her followers.

Several of the moderator variables were positively, although weakly, related to the outcome variable of follower resilience. The moderators that have a direct relationship with follower resilience include the leader-member exchange dimension of perceived contribution to the relationship $(r=.19, p<.05)$, the leader-member exchange dimension of loyalty $(r=.20, p<.05)$, as well as the variable measuring perceived cognitive similarities between supervisor and follower $(r=.18, p<.05)$.

\section{Test of Hypotheses}

\section{Direct relationship between supervisor resilience and authentic leadership.}

Hypothesis 1 proposed that there is a positive relationship between a supervisor's resilience and the supervisor's authentic leadership. A single regression equation with supervisor resilience as the predictor, and authentic leadership as the outcome, was used to test Hypothesis 1. The results indicated that supervisor's resilience was significantly related to authentic leadership $\left(\beta=.83, p<.01, R^{2}=.68, F(1,143)=308.69\right)$, thus supporting Hypothesis 1.

\section{Direct relationship between supervisor resilience and follower resilience.}

Hypothesis 2 proposed that there is a positive relationship between a supervisor's resilience and his or her followers' resilience. A single regression model with supervisor 
resilience as the predictor, and follower resilience as the outcome, was used to test Hypothesis 2. The results of this analysis failed to provide support for Hypothesis 2, as supervisor resilience was not related to follower resilience $\left(\beta=.10, p=.22, R^{2}=.01\right.$, $F(1,143)=1.55)$

Moderating effect of authentic leadership. Hierarchical multiple regression analyses were used to test Hypothesis 3, which proposed that the spillover effect of a supervisor's resilience onto follower's resilience varied as a function of the supervisor's authentic leadership. To minimize problems of multicollinearity (Aiken \& West, 1991), all variables, as well as the interaction term, were mean-centered prior to their entry into the model. Supervisor resilience and authentic leadership were entered in the first step of the regression analyses, but neither supervisor resilience $(\beta=.14, p=.33)$ nor authentic leadership $(\beta=-.05, p=.74)$ was significantly related to follower resilience (see Table 7). This suggests that, independent of one another, neither a supervisor's level of resilience nor the supervisor's authentic leadership has a direct relationship with followers' level of resilience.

In the second step, the interaction of supervisor resilience and authentic leadership was entered. There was significant interaction between supervisor resilience and authentic leadership $\left(\beta=.40, p<.01, \Delta R^{2}=.13, F(1,141)=21.35\right)$ (see Table 7$)$, thus providing support for Hypothesis 3, that the relationship between supervisor's resilience and follower's resilience varied depending on the supervisor's level of authentic leadership. 
Additional analyses were run to test the simple slopes (Aiken \& West, 1991) of the interaction between supervisor resilience and authentic leadership on follower resilience. Regression equations describing the relationship between supervisor resilience and follower resilience were calculated at one standard deviation above, and one standard deviation below the mean for authentic leadership, representing high and low levels of

Table 7

Hierarchical MRC for the Moderating Effect of Authentic Leadership

\begin{tabular}{llllr}
\hline & & \multicolumn{3}{c}{ Follower Resilience } \\
\cline { 3 - 5 } & & $R^{2}$ & $\Delta R^{2}$ & $\beta$ \\
\hline Step 1: & Supervisor Resilience & .01 & .01 & .14 \\
& Authentic Leadership & & & -.05 \\
Step 2: & Sup. Resilience X Authentic Leadership & $.14^{* *}$ & $.13^{* *}$ & $.40^{* *}$ \\
\hline
\end{tabular}

Note. ${ }^{*} p<.05,{ }^{* *} p<.01$

Beta values are reported from time of entry into model.

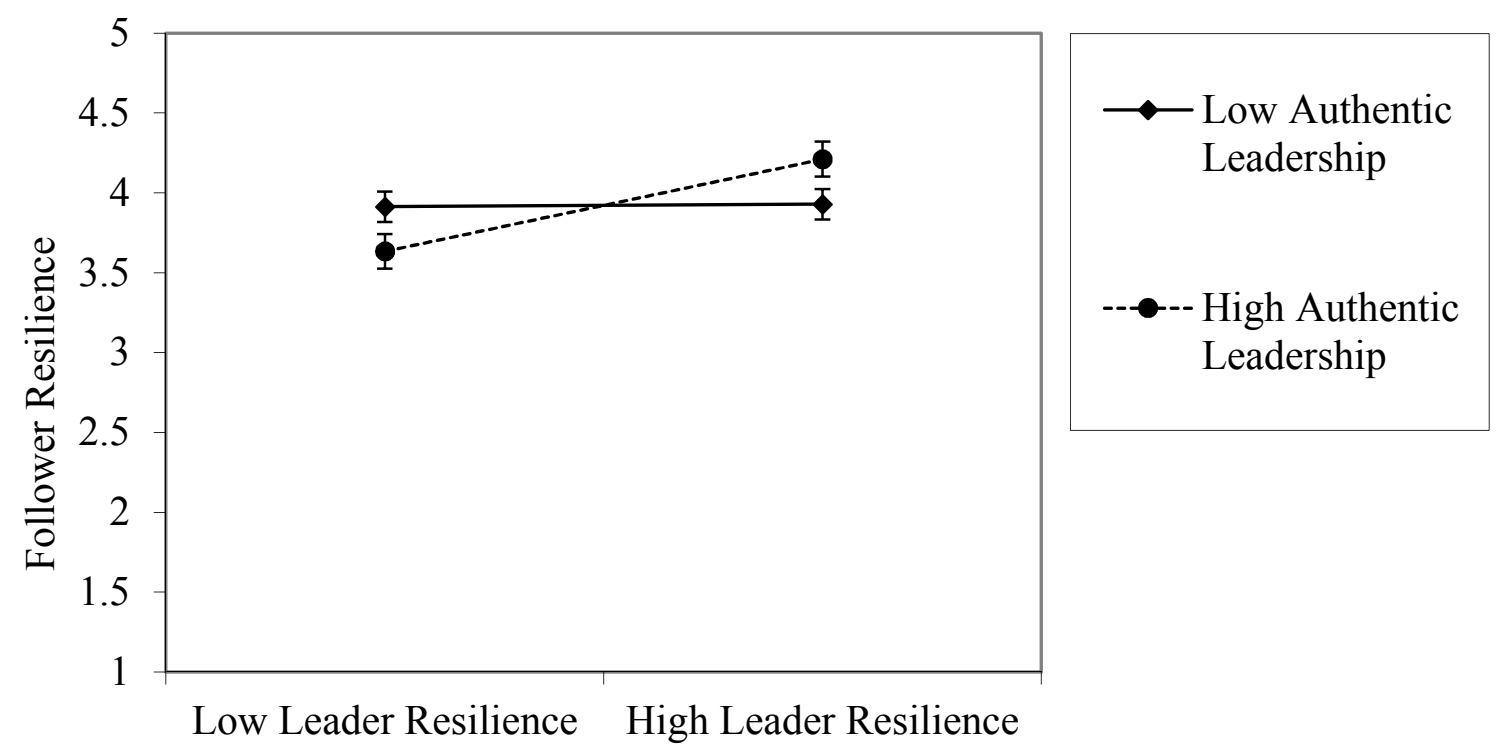

Figure 2. Moderating Effect of Authentic Leadership on the Relationship 
supervisor authentic leadership respectively. As seen in Figure 2, supervisors high in authentic leadership have a direct effect on their followers' level of resilience $(t=3.28, p$ $<.01$ ), such that followers are more likely to report being resilient when their leader is also highly resilient. However, leaders who are rated low in authentic leadership appear to have no statistically significant impact on their follower's level of resilience $(t=0.10$, $p=.92$ ), regardless of the leader's own level of resilience.

Moderating effect of relational demography. Hierarchical multiple regression analyses were used to test Hypothesis 4a, which proposed that the spillover effect of supervisor resilience onto follower resilience varied as a function of the perceived similarity between follower and supervisor. Given that the factor analysis identified two separate dimensions of perceived similarity, two separate analyses were conducted to test Hypothesis 4a. To minimize problems of multicollinearity (Aiken \& West, 1991), all variables, as well as the interaction term, were mean-centered prior to their entry into the model. The first analysis tested the moderating effects of perceived cognitive similarity between supervisor and follower. Supervisor resilience and perceived cognitive similarity were entered in the first step of the regression analyses, but neither supervisor resilience $(\beta=-.02, p=.84)$ nor perceived cognitive similarity $(\beta=.19, p=.08)$ was significantly related to follower resilience (see Table 8). This suggests that independent of one another, neither supervisor resilience nor the followers' perceived cognitive similarity with their supervisor had a direct relationship with followers' level of resilience. 
In the second step, the interaction of supervisor resilience and perceived cognitive similarity were entered. There was a significant interaction between supervisor resilience and perceived cognitive similarity $\left(\beta=.39, p<.01, \Delta R^{2}=.12, F(1,141)=19.48\right)$ (see Table 8), thus providing partial support for Hypothesis 4a, that the relationship between supervisor resilience and follower resilience varied depending on the followers' perceived cognitive similarity with their supervisor.

Table 8

Hierarchical MRC for the Moderating Effect of Perceived Cognitive Similarity

\begin{tabular}{llllc}
\hline & & \multicolumn{3}{c}{ Follower Resilience } \\
\cline { 3 - 5 } Step 1: & Supervisor Resilience & $R^{2}$ & $\Delta R^{2}$ & $\beta$ \\
& Cognitive Similarity & .03 & .03 & -.02 \\
Step 2: & Sup. Resilience X Cognitive Similarity & & & .19 \\
& & $.15^{* *}$ & $.12^{* *}$ & $.39^{* *}$
\end{tabular}
Note. ${ }^{*} p<.05,{ }^{* *} p<.01$

Beta values are reported from time of entry into model.

Additional analyses were run to test the simple slopes (Aiken \& West, 1991) of the interaction between supervisor resilience and perceived cognitive similarity on follower resilience. Regression equations describing the relationship between supervisor resilience and follower resilience were calculated at one standard deviation above, and one standard deviation below the mean for perceived cognitive similarity, representing high and low levels of perceived cognitive similarity respectively. As seen in Figure 3, the spillover of supervisor's resilience onto followers occurred only when there was a high degree of perceived similarity between supervisor and follower $(t=2.84, p<.01)$. 
Supervisor resilience appeared to have no statistically significant impact on follower resilience for those followers who perceived low levels of cognitive similarity with their $\operatorname{supervisor}(t=-1.41, p=.16)$.
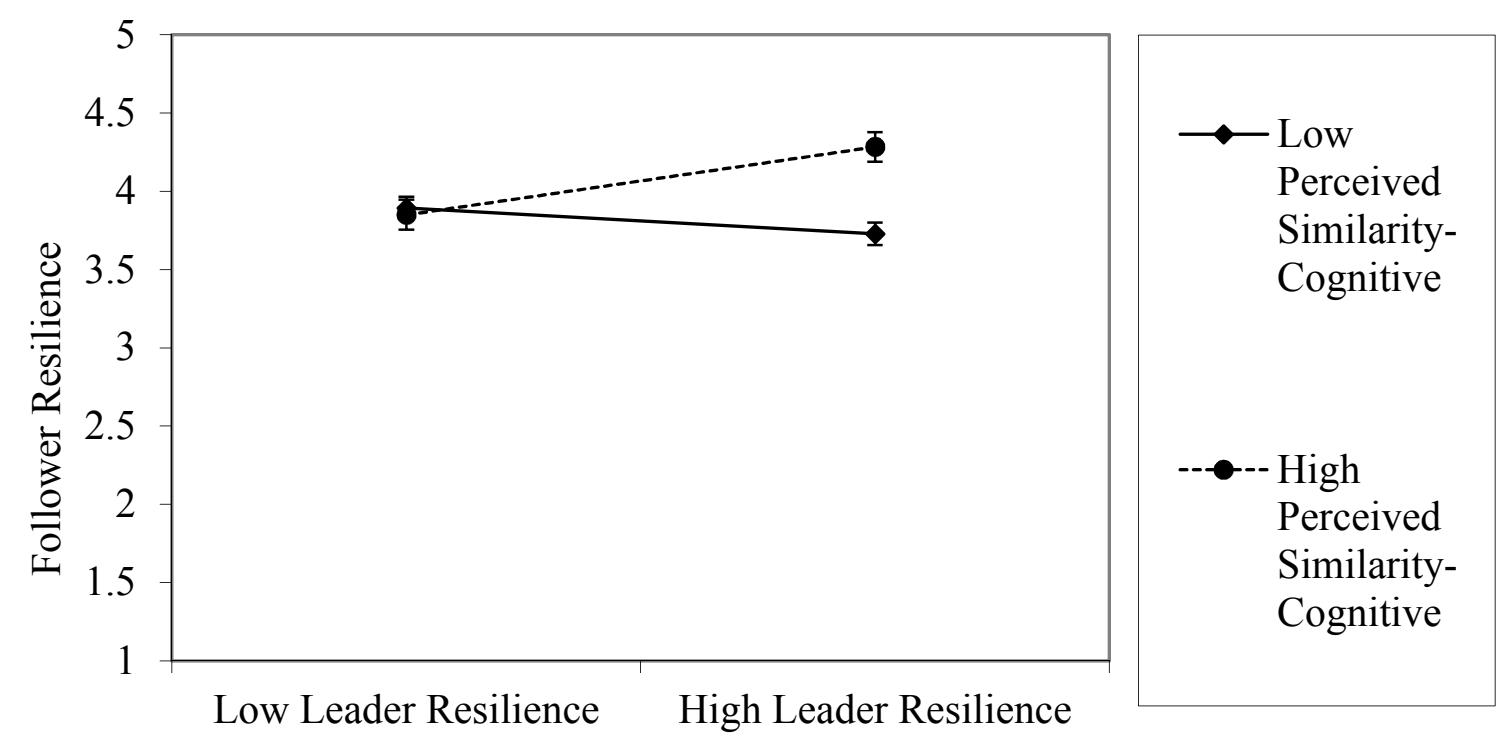

Figure 3. Moderating Effect of Perceived Cognitive Similarity on the Relationship between Leader Resilience and Follower Resilience

The second analysis for Hypothesis $4 \mathrm{a}$ tested the moderating effects of perceived demographic similarity between supervisor and follower. Supervisor resilience and perceived demographic similarity were entered in the first step of the regression analyses, and similar to previous results, neither supervisor resilience $(\beta=.10, p=.26)$ nor perceived demographic similarity $(\beta=.03, p=.69)$ was significantly related to follower resilience (see Table 9). This suggests that independent of one another, neither supervisor resilience nor the followers' perceived demographic similarity with their supervisor had a direct relationship with followers' level of resilience. 
In the second step, the interaction of supervisor resilience and perceived demographic similarity were entered. There was no significant interaction between supervisor resilience and perceived demographic similarity $(\beta=.79, p=.12)$ (see Table 9), thus failing to provide full support for Hypothesis 4a, that the relationship between supervisor's resilience and follower's resilience varied depending on the follower's perceived demographic similarity with his or her supervisor.

Table 9

Hierarchical MRC for the Moderating Effect of Perceived Demographic Similarity

\begin{tabular}{lllll}
\hline & & \multicolumn{3}{c}{ Follower Resilience } \\
\cline { 3 - 5 } & & $R^{2}$ & $\Delta R^{2}$ & $\beta$ \\
\hline Step 1: Supervisor Resilience & .01 & .01 & .10 \\
& Demographic Similarity & & & .03 \\
Step 2: Sup. Resilience X Demographic Similarity & .03 & .02 & .14 \\
\hline
\end{tabular}

Note. ${ }^{*} p<.05, * * p<.01$

Beta values are reported from time of entry into model.

Moderating effect of leader-member exchange. Hierarchical multiple regression analyses were used to test Hypothesis $4 \mathrm{~b}$, which proposed that the spillover effect of a supervisor's resilience onto follower's resilience varied as a function of the strength of the relationship between leader and follower, as measured by leader-member exchange. Given that the factor analysis identified three separate dimensions of leadermember exchange, three separate analyses were conducted to test Hypothesis $4 \mathrm{~b}$. To minimize problems of multicollinearity (Aiken \& West, 1991), all variables, as well as the interaction term, were mean-centered prior to their entry into the model. The first analysis tested the moderating effects of the dimension of LMX focused on the perceived 
contribution to the relationship. Supervisor resilience and perceived contribution were entered in the first step of the regression analyses. Similar to previous results, supervisor resilience $(\beta=.05, p=.57)$ was not significantly related to follower resilience, however the perceived contribution dimension of $\operatorname{LMX}(\beta=.18, p<.05)$ was significantly related to follower resilience (see Table 10).

In the second step, the interaction of supervisor resilience and perceived contribution were entered. There was a significant interaction between supervisor resilience and perceived contribution $\left(\beta=.17, p<.05, \Delta R^{2}=.03, F(1,141)=4.00\right)($ see Table 10), thus providing partial support for Hypothesis 4b, that the relationship between supervisor resilience and follower resilience varied depending on the followers' perceived contribution to the relationship with their supervisor.

Table 10

Hierarchical MRC for the Moderating Effect of LMX - Perceived Contribution

\begin{tabular}{lllll}
\hline & & \multicolumn{3}{c}{ Follower Resilience } \\
\cline { 3 - 5 } Step 1: & Supervisor Resilience & $R^{2}$ & $\Delta R^{2}$ & $\beta$ \\
& LMX-Perceived Contribution & .04 & .04 & .05 \\
Step 2: & Sup. Resilience X LMX-Perceived Contribution & $.07 *$ & $.03 *$ & $.18^{*}$ \\
& & & & \\
\hline Note. ${ }^{*} p<.05, * * p<.01$ & &
\end{tabular}

Beta values are reported from time of entry into model.

Additional analyses were run to test the simple slopes (Aiken \& West, 1991) of the interaction between supervisor resilience and perceived contribution on follower resilience. Regression equations describing the relationship between supervisor resilience and follower resilience were calculated at one standard deviation above, and 
one standard deviation below the mean for the LMX dimension of perceived contribution to the relationship, representing high and low levels of perceived contribution respectively. The slopes for neither high nor low perceived contribution were significantly different from zero (see Figure 4), suggesting that the direct effects of perceived contribution to the relationship alone may be a better predictor of follower resilience, and thus failing to support Hypothesis $4 \mathrm{~b}$.

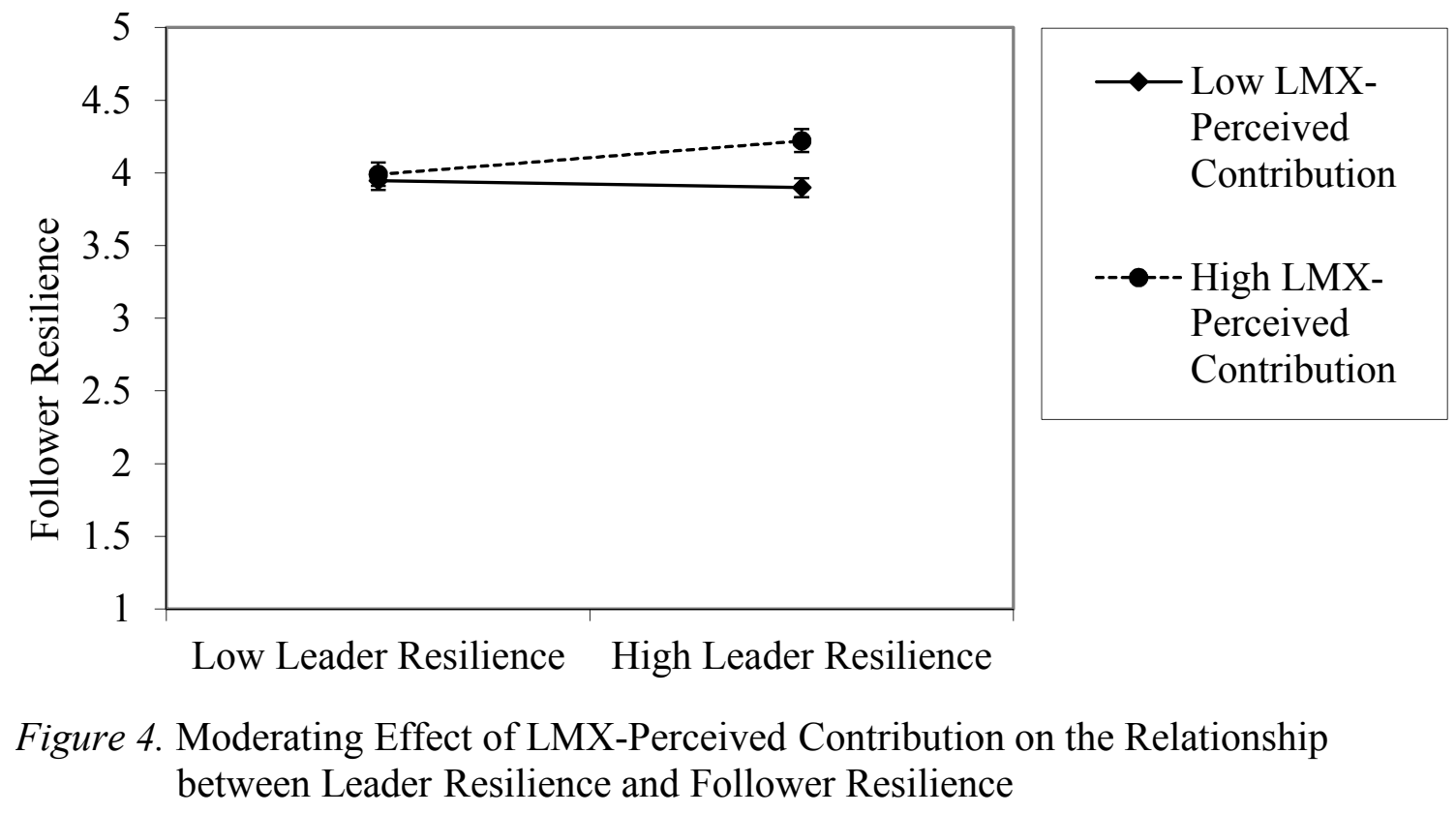

The second analysis tested the moderating effects of the LMX dimension of perceived loyalty in the relationship between supervisor and follower. Supervisor resilience and perceived loyalty were entered in the first step of the regression analyses. Similar to the perceived contribution dimension, supervisor resilience $(\beta=.04, p=.67)$ was not significantly related to follower resilience, however perceived loyalty $(\beta=.19, p$ $<.05$ ) was significantly related to follower resilience (see Table 11). 
In the second step, the interaction of supervisor resilience and perceived loyalty were entered. There was a significant interaction between supervisor resilience and the LMX dimension of perceived loyalty $\left(\beta=.20, p<.05, \Delta R^{2}=.04, F(1,141)=5.39\right)$ (see Table 11), thus providing partial support for Hypothesis $4 \mathrm{~b}$, that the relationship between supervisor resilience and follower resilience varied depending on the strength of the relationship between leader and follower.

Table 11

Hierarchical MRC for the Moderating Effect of LMX - Loyalty

\begin{tabular}{lllll}
\hline & & \multicolumn{3}{c}{ Follower Resilience } \\
\cline { 3 - 5 } & & $R^{2}$ & $\Delta R^{2}$ & $\beta$ \\
\hline Step 1: & Supervisor Resilience & $.04^{*}$ & $.04^{*}$ & .04 \\
& LMX-Loyalty & & & $.19^{*}$ \\
Step 2: & Sup. Resilience X LMX-Loyalty & $.08^{*}$ & $.04^{*}$ & $.20^{*}$ \\
\hline
\end{tabular}

Note. ${ }^{*} p<.05, * * p<.01$

Beta values are reported from time of entry into model.

Additional analyses were run to test the simple slopes (Aiken \& West, 1991) of the interaction between supervisor resilience and perceived loyalty on follower resilience. Regression equations describing the relationship between supervisor resilience and follower resilience were calculated at one standard deviation above, and one standard deviation below the mean for perceived loyalty, representing high and low levels of perceived loyalty respectively. As with previous results, the spillover of supervisor's resilience onto followers occurred only when there was a high degree of perceived loyalty between supervisor and follower $(t=1.99, p<.01)$ (see Figure 5). The supervisor's level of resilience appeared to have no statistically significant impact on his 
or her follower's level of resilience for those followers who perceived low levels of loyalty in the relationship with their supervisor $(t=-0.57, p=.57)$.

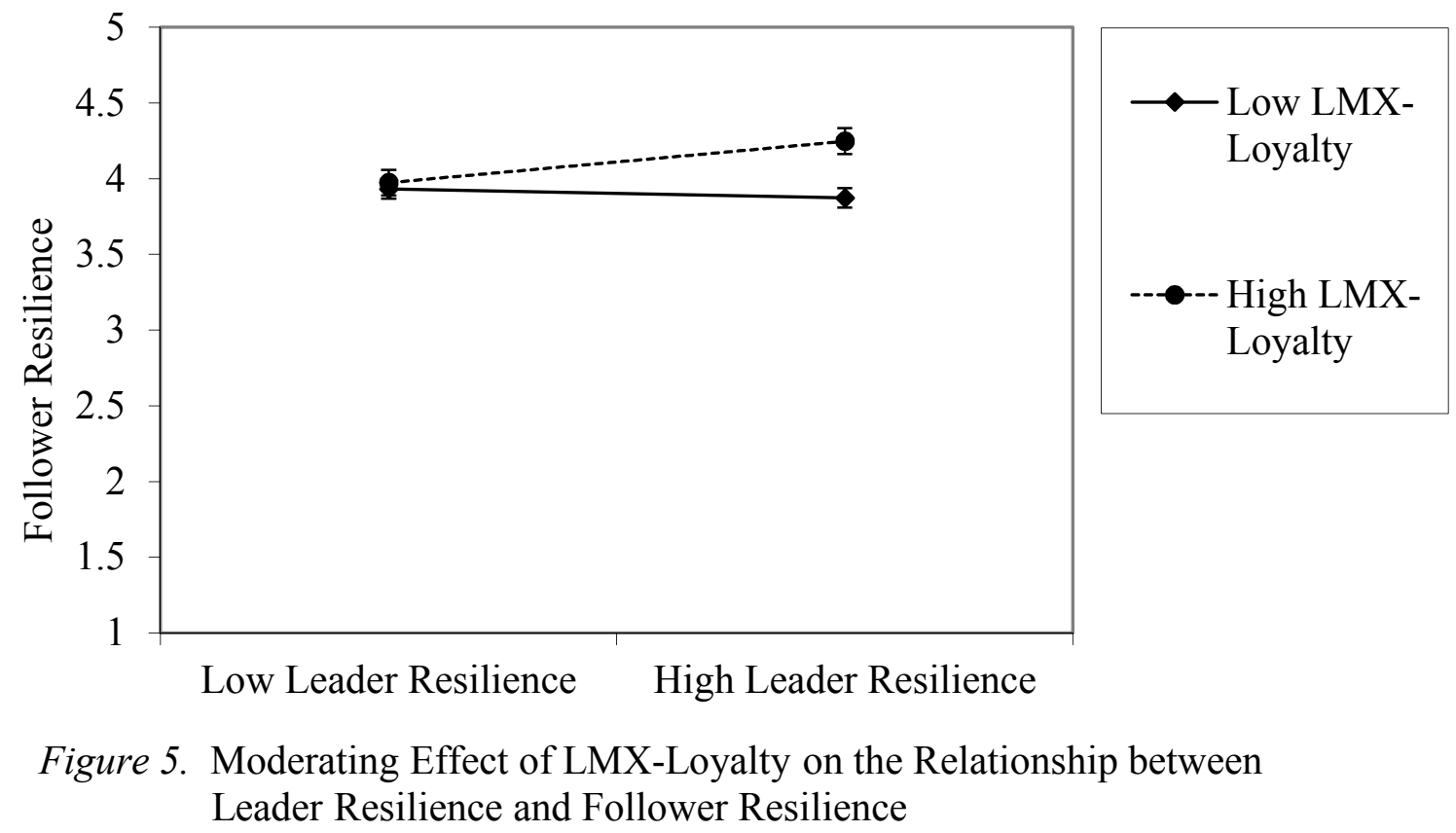

The final analysis used to test Hypothesis $4 \mathrm{~b}$ examined the moderating effects of the LMX dimension of affect. Supervisor resilience and LMX-affect were entered in the first step of the regression analyses, and neither supervisor resilience $(\beta=.09, p=.46)$, nor affect $(\beta=.03, p=.82)$ was significantly related to follower resilience (see Table 12 ).

In the second step, the interaction of supervisor resilience and affect was entered. There was a significant interaction between supervisor resilience and the LMX dimension of affect $\left(\beta=.41, p<.01, \Delta R^{2}=.13, F(1,141)=20.62\right)$ (see Table 12), thus providing partial support for Hypothesis $4 \mathrm{~b}$, that the relationship between supervisor's resilience and follower's resilience varied depending on the strength of the relationship between leader and follower. Additional analyses were run to test the simple slopes (Aiken \& 
West, 1991) of the interaction between supervisor resilience and affect on follower resilience. Regression equations describing the relationship between supervisor resilience and affect were calculated at one standard deviation above, and one standard deviation below the mean for affect, representing high and low levels of affect. As with previous results, the spillover of supervisor's resilience onto followers occurred only within followers who reported being satisfied with the relationship with their leader ( $t=$ $3.43, p<.01$ ) (see Figure 6). The supervisor's level of resilience appeared to have no statistically significant impact on his or her follower's level of resilience for those followers who perceived low levels of affect in the relationship with their supervisor $(t=$ $-0.76, p=.45)$. 
Table 12

Hierarchical MRC for the Moderating Effect of LMX - Affect

\begin{tabular}{lllll}
\hline & & \multicolumn{3}{c}{ Follower Resilience } \\
\cline { 3 - 4 } Step 1: & Supervisor Resilience & $R^{2}$ & $\Delta R^{2}$ & $\beta$ \\
\cline { 2 - 4 } Step 2: & Sup. Resilience X LMX-Affect & .01 & .01 & .09 \\
& & & .03 \\
& & $.14^{* *}$ & $.13^{* *}$ & $.41^{* *}$ \\
\hline
\end{tabular}

Note. ${ }^{*} p<.05, * * p<.01$

Beta values are reported from time of entry into model.
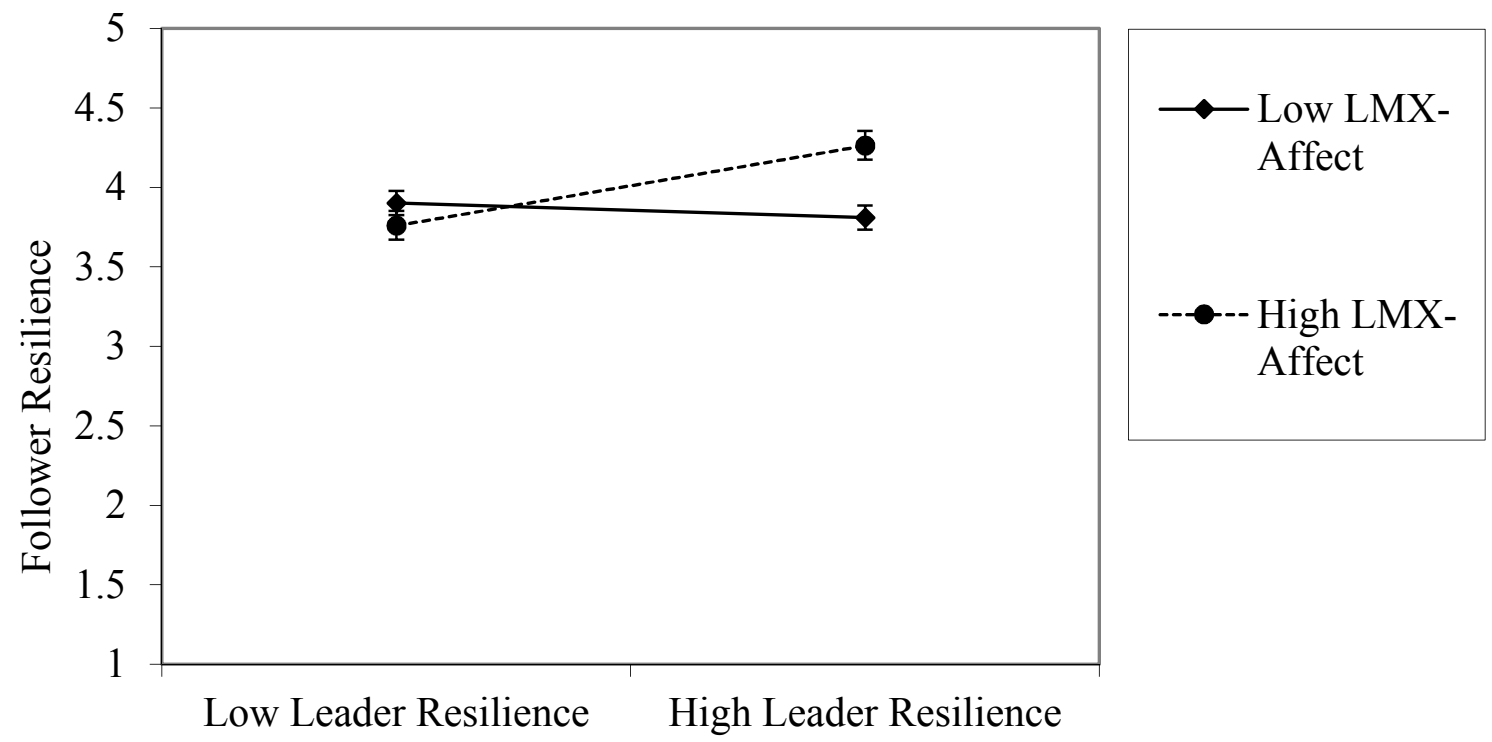

Figure 6. Moderating Effect of LMX-Affect on the Relationship 


\section{Discussion}

\section{Overall Findings}

The purpose of the present study was to explore the relationship between leader resilience and the potential spillover of this positive psychological trait onto followers. In addition to the direct effects of leader resilience on followers, potential moderators were also explored, including authentic leadership, relational demography, and leader-member exchange. Although the findings of this study suggest there is no direct relationship between leader resilience and follower resilience, the addition of moderators in the relationship yielded several interesting results. Furthermore, the findings of this study support previous research (Avolio et al., 2004; Avolio, \& Gardner, 2005; Gardner et al., 2005; Harland et al., 2005; Luthans, Vogelgesang, \& Lester, 2006), indicating that the positive psychological state of resilience is strongly related to authentic leadership.

Authentic leadership significantly moderated the relationship between leader and follower resilience, such that followers were more likely to be resilient when their supervisor displayed high levels of resilience as well as high levels of authentic leadership. The results of the simple slope analysis suggest that followers' resilience may not be affected by the leaders' resilience when the leader is perceived as being less authentic, indicating that the relationship may only be positive in nature. One possible explanation for these results is that highly resilient leaders who are inauthentic may be behaving in a way that allows them to recover from a failure, but at the expense of others, particularly their followers. 
Although originally hypothesized as a single dimension, the results of the moderated regression support the findings of the factor analysis, strongly indicating that employees' perceived similarity with their supervisor appears to have two components. The first component is perhaps best thought of as a deeper-level of similarity (Harrison, Price, \& Bell, 1998), and is related to perceived similarity in terms of thoughts and actions. The second component appeared to be a more surface-level similarity in terms of age and ethnicity. Employees who perceived a high degree of similarity with their leader in terms of the way they think and behave were more likely to have higher resilience when their supervisor also had high resilience. However, employees who did not perceive themselves as being cognitively similar to their supervisor did not appear to have a difference in their own resilience, regardless of the level of resilience of their leader.

The results of the analyses examining the surface-level similarity between leader and follower indicate that neither demographic similarities nor differences have an impact on the spillover of leader resilience onto followers. This suggests the spillover of resilience is a function of a deeper-level connection between leader and follower, and may not be influenced by surface-level characteristics. Alternatively, employees may not perceive demographics as a salient characteristic in the positive modeling dynamic described by Bandura (1997).

The final set of analyses examined the moderating role of the three dimensions of leader-member exchange on the relationship between leader and follower resilience. The first of these three dimensions was perceived contribution to the relationship, and 
although there was a significant interaction between perceived contribution and supervisor resilience on follower resilience, the simple slopes analyses indicate there is no difference in followers' resilience levels, regardless of the leaders' resilience. Indeed, the relatively low change in variance explained by the addition of the interaction effect of perceived contribution and supervisor resilience suggests that while the results may be statistically significant, the results lack practical significance.

The loyalty dimension of leader-member exchange significantly moderated the relationship between leader and follower resilience, such that employees reporting higher levels of loyalty in their relationship with their supervisor were more likely to have higher levels of resilience when their supervisor also had higher levels of resilience. Similar to the results for authentic leadership, the impact appears only to be significant when followers perceive a high degree of loyalty to exist in their relationship with their leader. As suggested by the results for authentic leadership, it may be that followers only adopt the resilient behaviors of their leaders when they have trust in their leader. Highly resilient leaders who do not have a relationship built on loyalty are unlikely to inspire their followers to adopt their behaviors.

The final dimension of leader-member exchange was affect, and of the three dimensions of LMX, this dimension had the strongest moderating impact on the spillover of leader resilience onto followers. As with the results of the previous significant moderators, the relationship between the leader's level of resilience only impacts follower's resilience when the follower reported feeling a strong affective component in the relationship. Although taken together the results of the analyses examining authentic 
leadership and the loyalty dimension of LMX suggest there must be a high level of trust between the leader and follower in order for resilience to transfer, the addition of the affect dimension suggests there must also be a strong social connection between the leader and follower as well.

\section{Theoretical Implications}

The present study has several valuable theoretical implications. This study expands upon our current understanding of the important role resilience plays in the development of authentic leadership, and provides further evidence that resilience is a valuable construct in predicting authentic leadership in individuals. Additionally, the results of the factor analyses of supervisor resilience and self-resilience indicate that individuals may have a more nuanced assessment of their own resilience, suggesting that the measurement of resilience may need further refinement. This study has also extended the understanding of the complex mechanisms underlying the transfer of positive psychological states between individuals. Prior literature has examined the role of positive psychological capital and authentic leadership (Avolio et al., 2004; Jensen, \& Luthans, 2006), and espoused the beneficial relationship between a supervisor's authentic leadership and their followers' development (Avolio, \& Gardner, 2005). However, relatively little research has explored the transference of positive psychological states from leader to follower. The inclusion of multiple moderating variables focused on the relationship between leader and follower lends support to the argument that the broaden and build theory explains both within-individual increases in positive psychological states, as well as between-individual spillover. 


\section{Practical Implications}

Perhaps the most valuable contribution of the present study is the practical implications for organizations looking to improve the resilience of their workforce. Resilience as a predictor of authentic leadership benefits from having excellent face validity (Connor, \& Davidson, 2003); job candidates are likely to be more accepting of questions regarding their ability to cope with stressors than questions regarding less clearly job-related concepts, such as optimism and hope. The measurement of resilience also lends itself to a variety of candidate assessment methods, including structured interviews, work sample tests, and assessment centers. The wide applicability and potentially strong validity of resilience make this construct a valuable selection criterion for a variety of organizations. The applications of resilience as a measurement tool are not limited to employee selection.

The results of this study also have strong implications for succession planning, providing robust and accurate methods of testing for resilience within employees and job candidates that can assist organizations in efforts to identify individuals who have the potential to become authentic leaders who are able to thrive in uncertain business environments. In addition to identifying potential leaders, the results of this study suggest that when looking to develop the resilience of employees, managers must be cognizant of the way in which they demonstrate their leadership skills, as well as the strength of the relationship they have with their employees. 


\section{Strengths}

One of the strengths of this study was that all participants included in the analyses were employed at least part-time, and reported working in a variety of industries. In addition to the variety of employment situations, the final sample of participants was diverse in terms of gender and ethnicity. The mix of employment situations and diversity within the sample provides a measure of confidence in the generalizability of the results. Another strength of this study was that the survey items used to assess resilience, authentic leadership, and the strength of the relationship between leader and follower are all drawn from well-established measures. The results of the factor analyses reported in the methods section provided additional support for the strong reliability of these measures.

\section{Limitations and Future Research}

As with most research, there are limitations within this study. Although the focus of the present study was on resilience, to fully capture the unique role of resilience would require measuring the other three positive psychological capital dimensions of hope, optimism, and self-efficacy. Future research should continue to examine the unique role of each dimension of positive psychological capital in predicting authentic leadership. Given the retrospective nature of resilience described earlier, and the synergistic effects of positive psychological capital, it may indeed be valuable to examine all four dimensions of positive psychological capital using structural equation modeling to identify antecedents and outcomes within the theory itself. 
The results of the factor analyses, taken with the low reliability values for the leader-member exchange dimension of perceived contribution to the relationship, as well as the low reliability values for the perceived demographic similarity items indicate potential issues with the instruments used to measure important moderator variables within this study. Although the leader-member exchange items have been tested for validity (Schriesheim et al., 1992), future research replicating these results using an alternative measure of leader-member exchange would lend confidence to the results presented within this study. As mentioned in the methods section, the perceived demographic similarity items were developed specifically for this study, and thus have no prior empirical evidence to validating their use. As with the leader-member exchange items, additional research is needed to fully understand the role that demography plays in the relationship between supervisor and follower resilience.

The relatively young age of participants is an additional limitation within this study. Given that resilience is theorized as developing over an individual's lifetime, younger employees may not have had adequate time to develop their resilience. Although on average participants reported a fairly high degree of resilience, it is possible that younger employees have not had adequate opportunities to experience significant challenges, thus leading them to inflate their assessment of their own resilience.

As briefly mentioned above, an additional limitation of the present study is the self-reported nature of the survey items. Although the perception of the relationship between follower and leader is most appropriately captured at the level of the follower, the nature of positive psychological capital may introduce issues of socially desirable 
responding. Future studies would benefit from examining both leaders' and followers' resilience using assessments from both individuals in the dyad. This depth of data collection would allow for analyses of discrepancies in self-reported versus otherreported positive psychological states that may yield a more detailed explanation of the spillover of positive psychological states between leaders and followers.

A serious limitation of this study was that data were collected at a single point in time, making it impossible to assess the causal nature of the measured variables. A longitudinal study measuring resilience and authentic leadership over time is needed to confidently assess the causal effects of a leader's resilience and authentic leadership on his or her followers' resilience.

Finally, researchers investigating the topic of resilience would benefit from examining additional moderating variables that were beyond the scope of this limited study. One example of such a moderator would be to expand upon demographic variables such as age, gender, and ethnicity; an examination of cultural differences may provide useful insight into differences in the development and transfer of resilience from a global perspective. Research into this topic could provide additional evidence of the generalizability of resilience as a positive psychological state that has direct impact on organizational performance (Walumbwa et al., 2008).

\section{Conclusion}

This study sought to examine the moderating role of authentic leadership and the strength of the relationship between leader and follower on the spillover of leader resilience onto followers. The findings of this study indicate that an authentic leader who 
has a strong rapport with his or her followers can strengthen their resilience. Thankfully, the converse does not appear to be true, as the results indicate that resilience does not decrease when leaders are viewed as inauthentic, or when the relationship between the leader and followers appears to be weak. For organizations seeking to increase the resiliency within their workforce, these findings are an encouraging indication that leaders can play a vital role in the development of this key trait. 


\section{References}

Aiken, L. S., \& West, S. G. (1991). Multiple regression: Testing and interpreting interactions. Newbury Park, CA: Sage.

Akyüz, Y. (2011). Global economic prospects: The recession may be over but where next? Global Policy, 2, 127-137.

Avey, J. B., Avolio, B. J., \& Luthans, F. (2011). Experimentally analyzing the impact of leader positivity on follower positivity and performance. The Leadership Quarterly, 22, 282-294.

Avey, J. B., Reichard, R. J., Luthans, F., \& Mhatre, K. H. (2011). Meta-analysis of the impact of positive psychological capital on employee attitudes, behaviors, and performance. Human Resource Development Quarterly, 22, 127-152.

Avey, J. B., Wernsing, T. S., \& Mhatre, K. H. (2011). A longitudinal analysis of positive psychological constructs and emotions on stress, anxiety, and well-being. Journal of Leadership \& Organizational Studies, 18, 216-228.

Avolio, B. J., \& Gardner, W. L. (2005). Authentic leadership development: Getting to the root of positive forms of leadership. The Leadership Quarterly, 16(3), 315-338.

Avolio, B. J., Gardner, W. L., Walumbwa, F. O., Luthans, F., \& May, D. R. (2004). Unlocking the mask: A look at the process by which authentic leaders impact follower attitudes and behaviors. The Leadership Quarterly, 15(6), 801-823.

Bandura, A. (1997). Self-efficacy: The exercise of control. New York: Freeman.

Bass, B. M. (1985). Leadership and performance beyond expectations. New York: Free Press.

Carroll, G. R., \& Khessina, O. M. (2005). Organizational and corporate demography. In D. L. Poston \& M. Micklin (Eds.), Handbook of Population (pp. 451-477). New York, NY: Springer.

Clapp-Smith, R., Vogelgesang, G. R., \& Avey, J. B. (2009). Authentic leadership and positive psychological capital the mediating role of trust at the group level of analysis. Journal of Leadership \& Organizational Studies, 15, 227-240. 
Conger, J. A., \& Kanungo, R. N. (1987). Toward a behavioral theory of charismatic leadership in organizational settings. Academy of Management Review, 12, 637647.

Connor, K. M., \& Davidson, J. R. (2003). Development of a new resilience scale: The Connor $\square$ Davidson resilience scale (CD $\square$ RISC). Depression and Anxiety, 18, 7682.

Coutu, D. L. (2002). How resilience works. Harvard Business Review, 80(5), 2-8.

Dansereau, F., Graen, G., \& Haga, W. J. (1975). A vertical dyad linkage approach to leadership within formal organizations: A longitudinal investigation of the role making process. Organizational Behavior and Human Performance, 13, 46-78.

Douglas, C. (2012). The moderating role of leader and follower sex in dyads on the leadership behavior-leader effectiveness relationships. The Leadership Quarterly, $23,163-175$.

Fredrickson, B. L. (2003). The value of positive emotions: The emerging science of positive psychology is coming to understand why it's good to feel good. American Scientist, 91, 330-335.

Gardner, W. L., Avolio, B. J., Luthans, F., May, D. R., \& Walumbwa, F. (2005). "Can you see the real me?" A self-based model of authentic leader and follower development. The Leadership Quarterly, 16, 343-372.

Gerstner, C. R., \& Day, D. V. (1997). Meta-Analytic review of leader-member exchange theory: Correlates and construct issues. Journal of Applied Psychology, 82, 827844.

Giallonardo, L. M., Wong, C. A., \& Iwasiw, C. L. (2010). Authentic leadership of preceptors: predictor of new graduate nurses' work engagement and job satisfaction. Journal of Nursing Management, 18, 993-1003.

Graen, G. B., \& Uhl-Bien, M. (1995). Relationship-based approach to leadership: Development of leader-member exchange (LMX) theory of leadership over 25 years: Applying a multi-level multi-domain perspective. The Leadership Quarterly, 6, 219-247.

Greenleaf, R. K. (1977). Servant leadership: A journey into the nature of legitimate power and greatness. Mahwah, NJ: Paulist Press.

Gucciardi, D. F., Jackson, B., Coulter, T. J., \& Mallett, C. J. (2011). The ConnorDavidson Resilience Scale (CD-RISC): Dimensionality and age-related 
measurement invariance with Australian cricketers. Psychology of Sport and Exercise, 12, 423-433.

Hamel, G. (2002). Leading the revolution: How to thrive in turbulent times by making innovation a way of life. Boston: Harvard Business School Press.

Harland, L., Harrison, W., Jones, J. R., \& Reiter-Palmon, R. (2005). Leadership behaviors and subordinate resilience. Journal of Leadership \& Organizational Studies, 11(2), 2-14.

Harrison, D. A., Price, K. H., \& Bell, M. P. (1998). Beyond relational demography: Time and the effects of surface-and deep-level diversity on work group cohesion. Academy of Management Journal, 41, 96-107.

Ilies, R., Morgeson, F. P., \& Nahrgang, J. D. (2005). Authentic leadership and eudaemonic well-being: Understanding leader-follower outcomes. The Leadership Quarterly, 16, 373-394.

Jensen, S. M., \& Luthans, F. (2006). Relationship between entrepreneurs' psychological capital and their authentic leadership. Journal of Managerial Issues, 18, 254-273.

Karaevli, A., \& Hall, D. T. T. (2003). Growing leaders for turbulent times: Is succession planning up to the challenge? Organizational Dynamics, 32, 62-79.

Kernis, M. H. (2003). Toward a conceptualization of optimal self-esteem. Psychological Inquiry, 14, 1-26.

Lindgren, C., Garcia, G., \& Saal, M. (1996). Banking Soundness and Macroeconomic Policy. International Monetary Fund, Washington, DC.

Luthans, F. (2002). The need for and meaning of positive organizational behavior. Journal of Organizational Behavior, 23, 695-706.

Luthans, F., Avey, J. B., Avolio, B. J., Norman, S. M., \& Combs, G. M. (2006). Psychological capital development: Toward a micro-intervention. Journal of Organizational Behavior, 27, 387-393.

Luthans, F., Avolio, B. J., Avey, J. B., \& Norman, S. M. (2007). Positive psychological capital: Measurement and relationship with performance and satisfaction. Personnel Psychology, 60, 541-572.

Luthans, F., Luthans, K. W., \& Luthans, B. C. (2004). Positive psychological capital: Beyond human and social capital. Business Horizons, 47(1), 45-50. 
Luthans, F., Vogelgesang, G. R., \& Lester, P. B. (2006). Developing the psychological capital of resiliency. Human Resource Development Review, 5, 25-44.

Masten, A. S. (2001). Ordinary magic: Resilience processes in development. American Psychologist, 56, 227-238.

Michie, S., \& Gooty, J. (2005). Values, emotions, and authenticity: Will the real leader please stand up? The Leadership Quarterly, 16, 441-457.

Mills, J. M., Fleck, C. R., \& Kozikowski, A. (2013). Positive psychology at work: A conceptual review, state-of-practice assessment, and a look ahead. The Journal of Positive Psychology, 8, 153-164.

Neider, L. L., \& Schriesheim, C. A. (2011). The authentic leadership inventory (ALI): Development and empirical tests. The Leadership Quarterly, 22, 1146-1164.

Peterson, S. J., Walumbwa, F. O., Byron, K., \& Myrowitz, J. (2009). CEO positive psychological traits, transformational leadership, and firm performance in hightechnology start-up and established firms. Journal of Management, 35, 348-368.

Povah, L. (2012). Assessing leaders for the future. Industrial and Commercial Training, $44,250-258$.

Rego, A., Sousa, F., Marques, C., \& eCunha, M. P. (2014). Hope and positive affect mediating the authentic leadership and creativity relationship. Journal of Business Research, 67, 200-210.

Richardson, G. E. (2002). The metatheory of resilience and resiliency. Journal of Clinical Psychology, 58, 307-321.

Ryff, C., \& Singer, B. (2003). Flourishing under fire: Resilience as a prototype of challenged thriving. In C. Keyes \& J. Haidt (Eds.), Flourishing: Positive psychology and the life well-lived (pp. 15-36). Washington, DC: American Psychological Association.

Schriesheim, C. A., Neider, L. L., Scandura, T. A., \& Tepper, B. J. (1992). Development and preliminary validation of a new scale (LMX-6) to measure leader-member exchange in organizations. Educational and Psychological Measurement, 52, $135-147$.

Seligman, M. (2002). Authentic happiness: Using the new positive psychology to realize your potential for lasting happiness. New York: Free Press. 
Shambaugh, R. (2010). The secrets of resilient leaders. Leader to Leader, 2010(58), 3944.

Shamir, B., \& Eilam, G. (2005). "What's your story?” A life-stories approach to authentic leadership development. The Leadership Quarterly, 16, 395-417.

Shin, S. J., \& Zhou, J. (2007). When is educational specialization heterogeneity related to creativity in research and development teams? Transformational leadership as a moderator. Journal of Applied Psychology, 92, 1709-1721.

Stiglitz, J. E. (2000). Capital market liberalization, economic growth, and instability. World Development, 28, 1075-1086.

Tsui, A. S., \& Egan, T. D. (1994). Performance implications of relational demography in vertical dyads. Paper presented at the Academy of Management annual meeting, Dallas, TX.

Tsui, A. S., Egan, T. D., \& O'Reilly, C. A. (1992). Being different: Relational demography and organizational attachment. Administrative Science Quarterly, 549-579.

Tsui, A. S., \& O'Reilly, C. A. (1989). Beyond simple demographic effects: The importance of relational demography in superior-subordinate dyads. Academy of Management Journal, 32, 402-423.

Tsui, A.S., Xin, K.R., \& Egan, T.D. (1994). Relational demography: The missing link in vertical dyad linkage. Paper presented at the American Psychological Association Conference on Diversity, Greensboro, NC.

Tugade, M. M., \& Fredrickson, B. L. (2004). Resilient individuals use positive emotions to bounce back from negative emotional experiences. Journal of Personality and Social Psychology, 86, 320-333.

Turban, D. B., \& Jones, A. P. (1988). Supervisor-subordinate similarity: types, effects, and mechanisms. Journal of Applied Psychology, 73, 228-234.

Walumbwa, F. O., Avolio, B. J., Gardner, W. L., Wernsing, T. S., \& Peterson, S. J. (2008). Authentic leadership: Development and validation of a theory-based measure. Journal of Management, 34, 89-126.

Wang, H., Sui, Y., Luthans, F., Wang, D., \& Wu, Y. (2014). Impact of authentic leadership on performance: Role of followers' positive psychological capital and relational processes. Journal of Organizational Behavior, 35, 5-21. 
Wong, C. A., \& Cummings, G. G. (2009). The influence of authentic leadership behaviors on trust and work outcomes of health care staff. Journal of Leadership Studies, 3(2), 6-23.

Youssef, C. M., \& Luthans, F. (2007). Positive organizational behavior in the workplace the impact of hope, optimism, and resilience. Journal of Management, 33, 774800 .

Zunz, S. J. (1998). Resiliency and burnout: Protective factors for human service managers. Administration in Social Work, 22(3), 39-54. 


\section{Appendix}

Survey Items

Self-Resilience (Gucciardi, Jackson, Coulter, \& Mallett, 2011)

1. I adapt to change.

2. I can deal with whatever comes.

3. I try to see the humorous side of problems.

4. Coping with stress can strengthen me.

5. I tend to bounce back after illness or hardship.

6. I can achieve goals despite obstacles.

7. I can stay focused under pressure.

8. I am not easily discouraged by failure.

9. I think of myself as strong person.

10. I can handle unpleasant feelings.

Supervisor Resilience (Gucciardi, Jackson, Coulter, \& Mallett, 2011)

1. My supervisor can adapt to change.

2. My supervisor can deal with whatever comes.

3. My supervisor tries to see the humorous side of problems.

4. My supervisor believes that coping with stress can strengthen them.

5. My supervisor tends to bounce back after illness or hardship.

6. My supervisor can achieve goals despite obstacles.

7. My supervisor can stay focused under pressure.

8. My supervisor is not easily discouraged by failure.

9. My supervisor thinks of them-self as strong person.

10. My supervisor can handle unpleasant feelings.

Authentic leadership (Neider \& Schriesheim, 2011)

- Self-awareness

1. My supervisor describes accurately the way that others view his/her abilities.

2. My supervisor shows that they understand their strengths and weaknesses.

3. My supervisor is clearly aware of the impact he/she has on others.

- Relational transparency

4. My supervisor clearly states what he/she means.

5. My supervisor openly shares information with others.

6. My supervisor expresses his/her ideas and thoughts clearly to others. 
- Internalized moral perspective

7. My supervisor shows consistency between his/her beliefs and actions.

8. My supervisor uses his/her core beliefs to make decisions.

9. My supervisor resists pressures to do things contrary to his/her beliefs.

10. My supervisor is guided in his/her actions by internal moral standards.

- Balanced processing

11. My supervisor asks for ideas that challenge his/her core beliefs.

12. My supervisor carefully listens to alternative perspectives before reaching a conclusion.

13. My supervisor objectively analyzes relevant data before making a decision.

14. My supervisor encourages others to voice opposing points of view.

Leader-member exchange (Schriesheim, Neider, Scandura, \& Tepper, 1992)

- Perceived contribution to the relationship

1. The way my supervisor sees it, the importance of my job to his/her performance is:

2. The way my supervisor sees me, he/she would probably say that my ability to do my job well is:

- Loyalty

3. My supervisor would probably say that my work goals and his/hers are:

4. I feel that my work goals and those of my supervisor are:

- $\quad$ Affect

5. On my present job, this is how I feel about the way my supervisor and I understand each other:

6. On my present job, this is how I feel about the way my supervisor provides help on hard problems:

Perceived Similarity (Turban \& Jones, 1988)

1. My supervisor and I see things in much the same way.

2. My supervisor and I are alike in a number of areas.

3. My supervisor and I are similar in age.

4. My supervisor and I are similar in regards to ethnicity. 